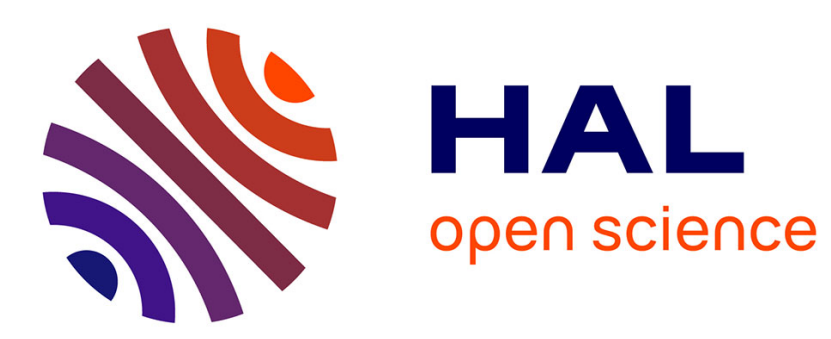

\title{
Cloud electrification and lightning activity in a tropical cyclone-like vortex
}

Christelle Barthe, Thomas Hoarau, Christophe Bovalo

\section{To cite this version:}

Christelle Barthe, Thomas Hoarau, Christophe Bovalo. Cloud electrification and lightning activity in a tropical cyclone-like vortex. Atmospheric Research, 2016, 180, pp.297-309. 10.1016/j.atmosres.2016.05.023 . hal-01330739

\section{HAL Id: hal-01330739 https://hal.science/hal-01330739}

Submitted on 27 Jun 2016

HAL is a multi-disciplinary open access archive for the deposit and dissemination of scientific research documents, whether they are published or not. The documents may come from teaching and research institutions in France or abroad, or from public or private research centers.
L'archive ouverte pluridisciplinaire HAL, est destinée au dépôt et à la diffusion de documents scientifiques de niveau recherche, publiés ou non, émanant des établissements d'enseignement et de recherche français ou étrangers, des laboratoires publics ou privés. 


\title{
Cloud electrification and lightning activity in a tropical cyclone-like vortex
}

\author{
C. Barthe ${ }^{\mathrm{a}, *}$, T. Hoarau ${ }^{\mathrm{a}}$, C. Bovalo ${ }^{\mathrm{b}}$ \\ a Laboratoire de l'Atmosphère et des Cyclones, UMR 8105 CNRS/Météo-France/Université de La Réunion, 15 avenue René Cassin, CS 92003,97744 Saint Denis Cedex 09, La Réunion, France \\ ${ }^{\mathrm{b}}$ Laboratoire d'Aérologie, UMR 5560 CNRS/Université de Toulouse, 14 avenue Edouard Belin, 31400 Toulouse, France
}

\begin{abstract}
A B S T R A C T
In this study, a high resolution simulation of an electrified tropical cyclone-like vortex was performed with the French mesoscale model Meso-NH coupled to an explicit electrical scheme. The objective was to analyze how graupel characteristics could influence the occurrence of lightning flashes in tropical cyclones. Two simulations were run: a control simulation using a 1-moment mixed phase bulk microphysical scheme, and a second simulation in which the parameters used to describe the graupel mass-diameter and fall speeddiameter relationships were modified to obtain smaller graupel fall speeds. Decreasing the graupel fall speed $\left(v_{g}\right)$ resulted in a weaker storm with a larger radius of maximum winds. For both simulated tropical cyclones, a deep mixed phase layer conducive to cloud electrification was observed. However, in the simulation where $v_{g}$ was decreased, the flash rate was almost zero throughout the simulation, whereas it reached a few flashes per minute in the control simulation. Several reasons that can explain this difference in the total flash rate are highlighted. Decreasing $v_{g}$ resulted in graupel being spread horizontally over a broader area by the secondary circulation. The more pronounced tilting observed with slower $v_{g}$ meant that poles of charges were not vertically aligned and thus the vertical electric field was reduced. In this study, the difference in the total flash rate mainly arose from changes in the mass and charge transfer rates due to changes in the parameters used to define the mass-diameter and particle-diameter relationships. Cloud electrification and lightning flashes being threshold-processes, a small change in the model physics can have a dramatic impact on the total flash rate.
\end{abstract}

\section{Introduction}

Over recent decades, the forecasting of tropical storm tracks has been greatly improved, mainly through a general increase in model horizontal resolution. However, forecasting storm intensity remains a key challenge for the scientific community. Factors at different temporal and spatial scales can impact tropical cyclone intensity. In particular, mesoscale and cloud-scale processes play a crucial role in the system dynamics and precipitation. Among the internal factors that may impact the variation of intensity of the tropical cyclone, the role of microphysics has been highlighted.

Willoughby et al. (1984) and Lord et al. (1984) were the first to point out the importance of ice phase microphysics in the structure and evolution of the simulated vortex. Using an axisymmetric non-hydrostatic hurricane model, Lord et al. (1984) showed that melting of ice particles can produce and maintain downdrafts over tens of kilometers in the horizontal plane. Later, some studies showed the key role of condensation for latent heat release (Wu et al., 2009; Li et al., 2013b), the energy

\footnotetext{
* Corresponding author.

E-mail addresses: christelle.barthe@univ-reunion.fr (C. Barthe), thomas.hoarau@meteo.fr (T. Hoarau), christophe.bovalo@aero.obs-mip.fr (C. Bovalo).
}

source of the tropical cyclone. The microphysical structure, which determines the distribution of such heating, influences the dynamics of the system and its large-scale structure and behavior.

Most studies have pointed out the significant impact of the choice of cloud microphysics scheme on the storm structure and intensity. Using MM5 at $4 \mathrm{~km}$ horizontal resolution and varying the cloud microphysical processes in a 3-ice scheme, Zhu and Zhang (2006) found pronounced differences in hurricane intensity and inner core structures. In particular, removing graupel resulted in a weaker hurricane with a wider region of precipitation due to the enhanced horizontal advection of hydrometeors relative to the vertical fallouts. $\mathrm{Li}$ and $\mathrm{Pu}$ (2008) performed numerical simulations of Hurricane Bonnie (2005) with the WRF-ARW model at $3 \mathrm{~km}$ horizontal resolution and with different microphysical schemes. They showed that the difference in the simulated minimum sea level pressure (MSLP) varied by up to $10 \mathrm{hPa}$ for the four most advanced schemes.

The primary effect of graupel on the minimum sea level pressure and maximum surface wind speed, i.e. the indicators of tropical cyclone intensity, has been recognized. Using MM5 to simulate hurricane Bonnie (1998), Zhu and Zhang (2006) stated that, due to its rapid fallout, graupel helps narrow the dimension of the eyewall. McFarquhar et al. (2006) performed numerical experiments on hurricane Erin (2001) 
with the MM5 model at $2 \mathrm{~km}$ horizontal resolution. They showed that using higher graupel fall speed produced lower minimum sea level pressure. By increasing the graupel fall speed, Franklin et al. (2005) observed that graupel was mainly confined to the convective regions. Higher rain rates were also produced in the inner core of the storm.

However, the microphysical state of tropical storms is difficult to observe in detail because their tracks mainly pass over uninhabited ocean. Since the electrical state of the storm is deeply linked to its microphysical structure, lightning activity could be used to infer the microphysical state of the storm. Fierro et al. (2007) were the first to attempt simulations of an electrified hurricane-like vortex to investigate the microphysical and electrical structure of the storm. Their simulation of an idealized hurricane was carried out at $2 \mathrm{~km}$ horizontal resolution with the model developed by Straka and Mansell (2005), incorporating a cloud electrification and lightning scheme. Then Fierro et al. (2011) performed a simulation of hurricane Rita during its period of rapid intensification. They used the Los Alamos National Laboratory High Gradient model (Reisner and Jeffery, 2009) and included an electrification scheme based on that of Mansell et al. (2005). Given the cost of the calculations, lightning discharge was treated in a simple manner: when the electric field exceeded the breakeven electric field, the space charge density was decreased by a constant value of $10 \%$ through the column upon discharge. The fact that the horizontal extension of the lightning flashes was not taken into account could explain why the flash rate was overestimated. More recently, Fierro et al. (2015) produced a $350-\mathrm{m}$ resolution simulation of the electrification within a hurricane embedded in the general environment of hurricane Isaac (2012). The higher hurricane intensity, larger reflectivities and higher echo top than observed made the simulated lightning activity difficult to compare to observations.

In recent years, several studies have attempted to link lightning activity to changes in tropical storm intensity (Squires and Businger, 2008; Price et al., 2009; Abarca et al., 2011; Zhang et al., 2012; DeMaria et al., 2012; Bovalo et al., 2014; Whittaker et al., 2015; Zhang et al., 2015). However, owing to limitations inherent in the lightning observation networks, only cloud-to-ground (CG) flashes are treated in these studies or, if intra-cloud (IC) flashes are included in the analysis, only tropical storms near to the coast are considered due to the limited-area lightning networks used to detect IC (Fierro et al., 2011) or only partial coverage of lightning within tropical storms obtained from satellite observations (Cecil and Zipser, 1999; Cecil et al., 2002; Jiang et al., 2013). As shown by Bovalo et al. (2014), tropical storms have very different behavior according to whether they are in the open ocean or near the coasts.

The purpose of the present study is to analyze the electrical structure in the eyewall of a tropical cyclone-like vortex and the processes that are decisive for lightning flash triggering. For this purpose, a modeling study is conducted using the mesoscale model Meso-NH with an explicit electrical scheme. Due to the critical role of graupel in latent heat distribution (e.g. McFarquhar et al., 2006; Gao et al., 2006; Zhu and Zhang, 2006) and cloud electrification (e.g. Takahashi, 1978; Jayaratne et al., 1983; Saunders et al., 1991; Brooks et al., 1997), a sensitivity analysis changing the graupel characteristics is also performed. It underlines the physical processes that are important for cloud electrification and charge distribution in a tropical cyclone. We first present the numerical experiments. Then the dynamics and microphysics of the simulated tropical cyclone-like vortex are analyzed. Finally, the electrical state of the storm is discussed and physical processes responsible for cloud electrification and lightning triggering are explored.

\section{Numerical experiments}

\subsection{Meso-NH and the electrical scheme CELLS}

The mesoscale, non-hydrostatic atmospheric model Meso-NH used in this study was jointly developed by the Centre National de la
Recherche Météorologique (Météo-France and Centre National de la Recherche Scientifique) and the Laboratoire d'Aérologie (Université de Toulouse and Centre National de la Recherche Scientifique). This model is able to simulate both idealized systems at high resolution and real meteorological events over large domains with complex terrain. A full description of the model capabilities is available at http://mesonh.aero.obs-mip.fr/.

The Meso-NH model contains the cloud electrification and lightning scheme CELLS (Barthe et al., 2012). This scheme computes the bulk electric charge attached to each microphysical species (cloud droplets, rain, pristine ice crystals, snow/aggregates, graupel and hail) and to positive and negative free ions. Several parameterizations (Takahashi, 1978; Saunders et al., 1991; Saunders and Peck, 1998; Tsenova et al., 2013) of the dominant non-inductive charging process are included, together with an inductive charging process. The electric field is obtained by inverting the Gauss equation with an extension to terrain-following coordinates. A lightning flash is initiated when the electric field exceeds a breakdown field (Marshall et al., 1995). Flashes are composed of a bidirectional leader phase that represents the vertical extension from the triggering point. A phase obeying a fractal law is added to mimic the horizontal extension in electrically charged zones. Then electric charges are neutralized along the flash path. This electrical scheme in Meso-NH has successfully reproduced several idealized storms and the 10 July 1996 STERAO storm (Barthe and Pinty, 2007), the 21 July EULINOX storm (Barthe et al., 2012) and some HyMeX convective events (Pinty et al., 2013).

\subsection{Model setup and initialization}

The model was set up with triple two-way nested domains having horizontal grid spacings of 32 (D1), 8 (D2) and 2 (D3) km and grid sizes of $128 \times 100,360 \times 240$ and $480 \times 240$ points, respectively. The innermost domain was moved 3 times to keep the cyclone inner core in the highest resolution domain. In the vertical, 70 levels were used, with highest resolution near the surface. Note that the simulated storm was located in the southern hemisphere.

An analytic model was used to initialize the radial and vertical distribution of the tangential wind over the largest domain. The analytic wind, which varies with altitude and radius from the storm center, was defined through a simplified version of the formulation proposed by Holland (1980) and Nuissier et al. (2005). The initial horizontally homogeneous environment profile was derived from that of McBride and Zehr (1981). The sea surface temperature was set to $28.6^{\circ} \mathrm{C}$.

A first segment of the simulation with two nested domains (D1 and D2) was run for $24 \mathrm{~h}$. During this spin-up period, the subgrid-scale convection was parameterized by a mass-flux convection scheme (Bechtold et al., 2001), and microphysics was inactive, as in Fovell et al. (2009). After $24 \mathrm{~h}$, the domain D3 was introduced, encompassing the tropical cyclone inner core, and a bulk mixed phase microphysics scheme (Pinty and Jabouille, 1998) was activated. The microphysics scheme is a single-moment bulk scheme that predicts the mixing ratio of five microphysical species: cloud water $\left(r_{c}\right)$, rain $\left(r_{r}\right)$, cloud ice $\left(r_{i}\right)$, snow $\left(r_{s}\right)$ and graupel $\left(r_{g}\right)$. This scheme was derived from Lin et al. (1983). The convection scheme was still used in the two coarser resolution domains, while the convection was explicitly resolved in the innermost domain. At $48 \mathrm{~h}$ of simulation, the electrical scheme was introduced into the innermost domain and the simulation was run for an additional $48 \mathrm{~h}$. For the three domains, the turbulence parameterization was based on a 1.5-order closure (Cuxart et al., 2000) with purely vertical turbulent flux computations using the mixing length of Bougeault and Lacarrère (1989). The radiative scheme was the one used at ECMWF (Gregory et al., 2000) including the Rapid Radiative Transfer Model (RRTM) parameterization (Mlawer et al., 1997).

The explicit electrical scheme (Barthe et al., 2012) treats both cloud electrification and lightning triggering and propagation. Among several parameterizations available in the model (see Barthe and Pinty (2007) 
and Tsenova et al. (2013)), the parameterization developed by Saunders et al. (1991) was arbitrarily chosen. The charge transfer at low effective water content was reduced according to Helsdon et al. (2001). The inductive process was also taken into account (Ziegler et al., 1991).

\subsection{Sensitivity analysis}

Graupel fall speed has been shown to have an impact on the intensity of tropical storms (Franklin et al., 2005; McFarquhar et al., 2006). Since graupel is also a key element in cloud electrification via the noninductive process (Brooks et al., 1997; Saunders and Peck, 1998), the objective of this study was to investigate how a change in the graupel fall speed translated into lightning flash activity in a tropical cyclone.

In the 1-moment mixed phase microphysics scheme of Meso-NH, the parameters chosen for the graupel class corresponded to those of lump graupel. The values for the coefficients of the mass-diameter $\left(m(D)=a D^{b}\right)$ and velocity-diameter $\left(v(D)=c D^{d}\right)$ relationships were taken from Locatelli and Hobbs (1974). Two sets of parameters were considered. The reference simulation had $\left(a=19.6 \mathrm{~g} \mathrm{~m}^{-b}, b=2.8\right.$, $\left.c=124 \mathrm{~m}^{1-d} \mathrm{~s}^{-1}, d=0.66\right)$ while $\left(a=42 \mathrm{~g} \mathrm{~m}^{-b}, b=3, c=\right.$ $27.8 \mathrm{~m}^{1-d} \mathrm{~s}^{-1}, d=0.46$ ) corresponded to a simulation with lower density and more slowly falling graupel. It is worth noting that the objective of the sensitivity experiment is not to assess which set of $(a, b, c, d)$ parameters is best suited to simulate cloud electrification in tropical cyclones. It is rather to analyze how a change in the characteristics of the graupel can impact cloud electrification, and thus to explore the physical processes involved in tropical cyclone lightning.

\section{Model results}

\subsection{Storm track and intensity}

Fig. 1 displays the track and intensity from the two experiments: the control run (hereafter referred to as CTRL) and the run with lower graupel fall speed (hereafter referred to as SGFS). The tracks show no significant differences in direction or speed. This result is in agreement with previous numerical experiments by McFarquhar et al. (2006), Zhu and Zhang (2006) and Li et al. (2013b) that showed little impact of the microphysical schemes on the storm track. McFarquhar et al. (2006) and Li et al. (2013b) concluded that the large-scale flow was broadly responsible for determining the storm track. However, Fovell et al. (2009) showed that the average fall speed controlled the storm track through changes in the radial temperature gradients, which could impact the outer wind strengths.

In contrast, the simulated intensities, represented by the minimum sea level pressure, were obviously different in the two experiments. The intensity curves started to diverge at 48 h, i.e. $24 \mathrm{~h}$ after the microphysics scheme was activated. The SGFS storm experienced a slower intensification than the CTRL storm. The CTRL storm reached its maximum intensity ( $942.6 \mathrm{hPa}$ ) at $84 \mathrm{~h}$ while the SGFS storm had a maximum intensity of $954.6 \mathrm{hPa} 6 \mathrm{~h}$ later. A maximum 18-hPa difference occurred at $84 \mathrm{~h}$. The CTRL storm deepened at a rate of about $0.9 \mathrm{hPa} \mathrm{h}^{-1}$ in the period between 48 and $84 \mathrm{~h}$. The deepening rate of the SGFS storm was less than half the CTRL value $\left(0.4 \mathrm{hPa} \mathrm{h}^{-1}\right)$ during the same 36 -h period. Thus, using a slower $v_{g}$ tended to produce a system that intensified less and more slowly. This result is in agreement with McFarquhar et al. (2006), who showed that the coefficients used to describe $v_{g}$ affected the MSLP by up to $7 \mathrm{hPa}$, with higher $v_{g}$ giving lower MSLP.

\subsection{Storm structure}

Fig. 2 shows height-radius plots of some azimuthally averaged dynamical variables at $84 \mathrm{~h}$. This time corresponds to the peak intensity in the CTRL storm, and is also the time when the intensity difference is maximum between the CTRL and the SGFS cyclones. The azimuthally averaged maximum tangential wind $\left(v_{t}\right)$ is higher for the CTRL storm $\left(69 \mathrm{~m} \mathrm{~s}^{-1}\right)$ than for the SGFS storm $\left(59 \mathrm{~m} \mathrm{~s}^{-1}\right)$. This is consistent with the CTRL simulation producing a more intense tropical cyclone. The radius of maximum wind (RMW) is about $30 \mathrm{~km}$ and $40 \mathrm{~km}$ for the CTRL and SGFS storms, respectively. The eyewall outward slope, defined as the angle from the vertical axis to the axis of the maximum tangential wind, is $68^{\circ}$ for the CTRL and $74^{\circ}$ for the SGFS storm. This is consistent with the results of Stern et al. (2014). Using airborne Doppler radar data from 39 flights into hurricanes between 2009 and 2010, they found that the slope of the RMW increased with size.

As shown by the azimuthally averaged radial wind, the secondary circulation is stronger in the CTRL storm than in the SGFS one. At low levels and in the upper troposphere, the azimuthally averaged radial velocity $v_{r}$ is about $5 \mathrm{~m} \mathrm{~s}^{-1}$ higher in the CTRL storm compared to the SGFS storm. The azimuthally-averaged vertical velocity is consistently lower when the graupel fall speed is decreased.

Height-radius plots of some azimuthally-averaged microphysics variables are shown on Fig. 3. When the graupel fall speed is decreased, the cloud water mixing ratio has a larger horizontal extension below the freezing level. The axisymmetric cloud water mixing ratio exhibits a sharper gradient along the inner boundary of the eyewall in the CTRL storm (Fig. 3a). In both simulations, supercooled water is quite well transported at altitude by the eyewall updraft, with the $0.01 \mathrm{~g} \mathrm{~kg}^{-1}$ mixing ratio reaching $10 \mathrm{~km}$. This favors not only the homogeneous nucleation of cloud ice but also cloud electrification via the non-inductive parameterization that needs the presence of supercooled cloud droplets to occur (e.g. Takahashi, 1978; Jayaratne et al., 1983; Saunders et al., 1991). The maximum axisymmetric cloud water and cloud ice mixing
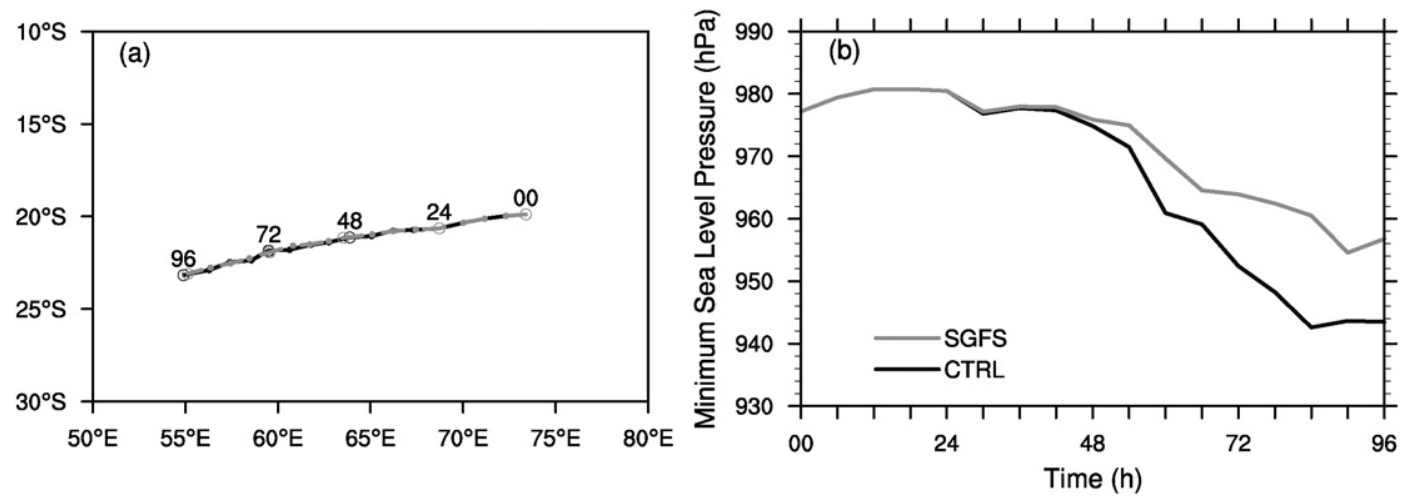

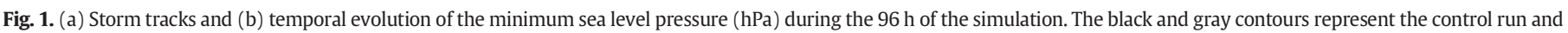
the simulation using lower graupel fall speed, respectively. 

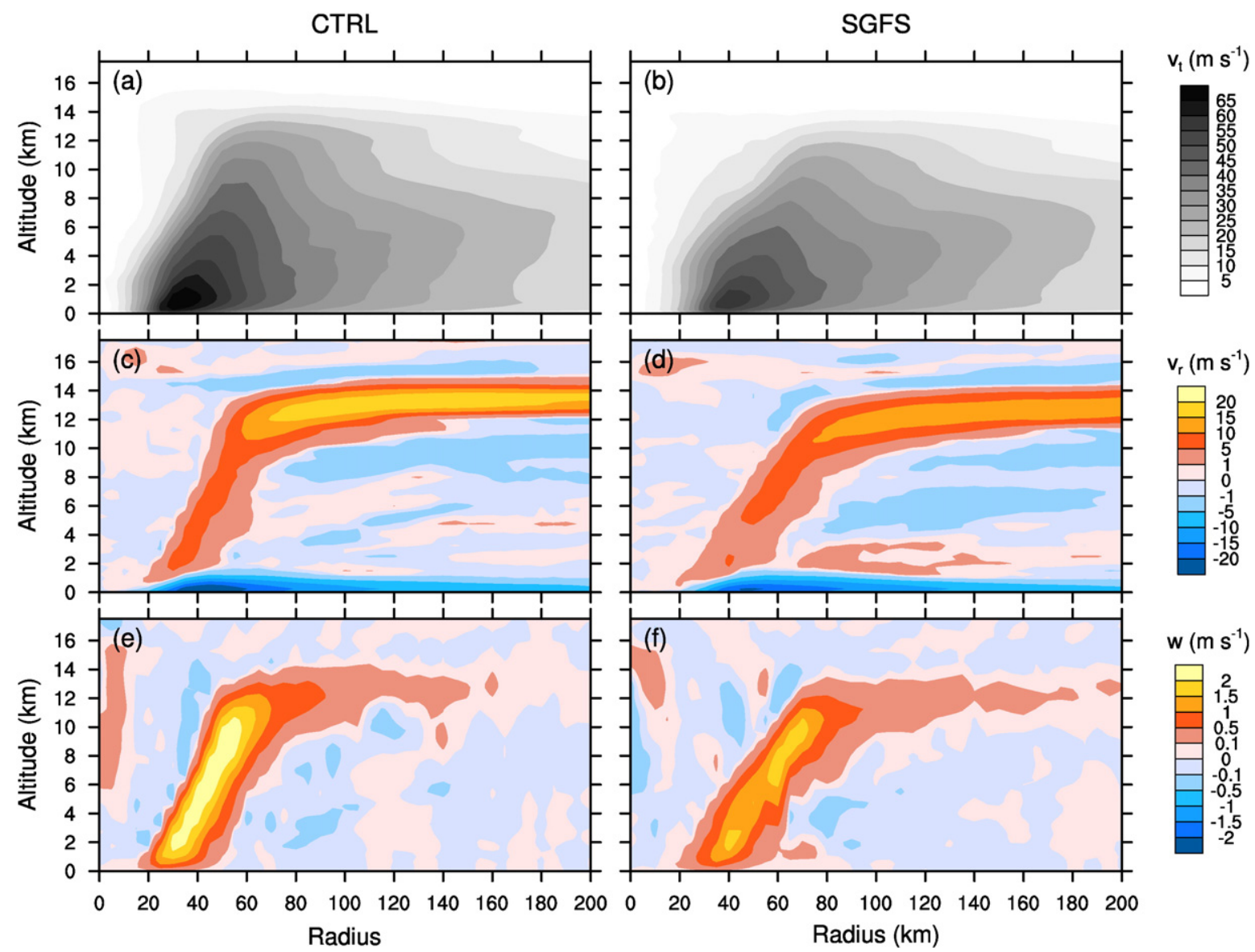

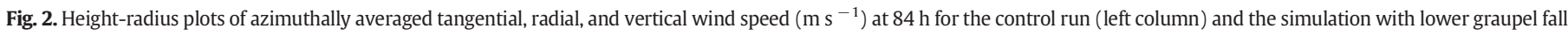
speed (right column).

ratios are well colocated with the axisymmetric updraft (Fig. 2). The altitudes of the maximum cloud water (1-5 km) and cloud ice (11 km) mixing ratios are similar to those found by Li et al. (2013a) in a WRF simulation of typhoon Hagupit. Graupel is mainly found in the eyewall, above the rainwater, which indicates that it partly originates from the melting of graupel. McFarquhar et al. (2006) stated that graupel with lower fall speed could be advected further for a given horizontal advection speed, and thus spread over larger areas. Less intense rain was then produced for lower graupel fall speed. For all types of hydrometeors, the maximum value of the azimuthally-averaged mixing ratio is higher in the CTRL storm. Consequently, the azimuthally-averaged radar reflectivity shows a lower maximum at low levels and exhibits a higher slope when the graupel fall speed is decreased. In both simulations, the $30 \mathrm{dBZ}$ contour extends several kilometers above the freezing level in the eyewall.

A height-radius plot of the azimuthally-averaged electric field modulus is also shown on Fig. 3. It clearly shows that the inner core region is electrified. The electric field modulus exceeds a few $\mathrm{kV} \mathrm{m}^{-1}$ in both simulations, which is much higher than the fair weather electric field (Gish, 1944). This is consistent with the conclusions of Reinhart et al. (2014), who explored the relationships between lightning and storm structure during hurricane Karl using aircraft data collected during the NASA Genesis and Rapid Intensification Processes (GRIP) experiment. They showed that electrified inner-core regions were generally associated with deep mixed-phase layers, and colocation of small ice particles, graupel and supercooled water. However, a decrease in the graupel fall speed has a significant impact on the electric field modulus. While it exceeds $20 \mathrm{kV} \mathrm{m}^{-1}$ in the CTRL storm, it barely reaches $10 \mathrm{kV} \mathrm{m}^{-1}$ in the SGFS storm. The origin of this difference and its impact on the lightning activity will be discussed below.

\subsection{Cloud variable distribution}

A more quantitative comparison of the CTRL and SGFS storm structure was assessed through contoured frequency by altitude diagrams (CFAD, Yuter and Houze (1995)). CFADs of simulated $w$ for the region within $120 \mathrm{~km}$ of the storm center at $84 \mathrm{~h}$ are shown on Fig. 4 for the CTRL and the SGFS simulations. In the CTRL simulation, more than $60 \%$ of the inner core vertical velocities range between -2 and $2 \mathrm{~m} \mathrm{~s}^{-1}$ (Fig. 4a). Black et al. (1996) found that $70 \%$ of the eyewall vertical velocities ranged between -2 and $2 \mathrm{~m} \mathrm{~s}^{-1}$. While downdrafts do not exceed $-6 \mathrm{~m} \mathrm{~s}^{-1}$, updrafts can reach $16 \mathrm{~m} \mathrm{~s}^{-1}$ between 5 and $7 \mathrm{~km}$ altitude. This value is consistent with the threshold of $10-12 \mathrm{~m} \mathrm{~s}^{-1}$ deduced by Zipser and Lutz (1994) for rapid electrification of convective cells. For the SGFS simulation, vertical velocities mainly range between -2 and $4 \mathrm{~m} \mathrm{~s}^{-1}$ and do not exceed $14 \mathrm{~m} \mathrm{~s}^{-1}$ (Fig. 4b). The difference between the CFAD of $w$ for SGFS and CTRL clearly shows that CTRL has a higher frequency of $w>4 \mathrm{~m} \mathrm{~s}^{-1}$ whatever the altitude.

The CFAD of radar reflectivity for the CTRL simulation (Fig. 4d) exhibits a classical structure. In the lower troposphere, radar reflectivity ranges mainly between 25 and $40 \mathrm{dBZ}$ and less than $1 \%$ of the grid points per altitude level reach $50 \mathrm{dBZ}$. Above $5 \mathrm{~km}$ altitude, and above the freezing level, the radar reflectivity modal and maximum values are both significantly reduced.

The CFAD of simulated hydrometeor mixing ratio $\left(r_{x}\right.$ with $x=$ $c, r, i, s, g)$ for the inner core region at $84 \mathrm{~h}$ are shown on Fig. 5. Generally, the difference between the CFAD of $r_{x}$ for SGFS and the CFAD of $r_{x}$ for CTRL shows that the CTRL simulation has larger frequencies of high mixing ratio. The difference between the two simulations is more noticeable for ice crystals, rain and graupel, with the $0.01 \%$ contour reaching higher mixing ratio values for the CTRL run than for the SGFS 
CTRL
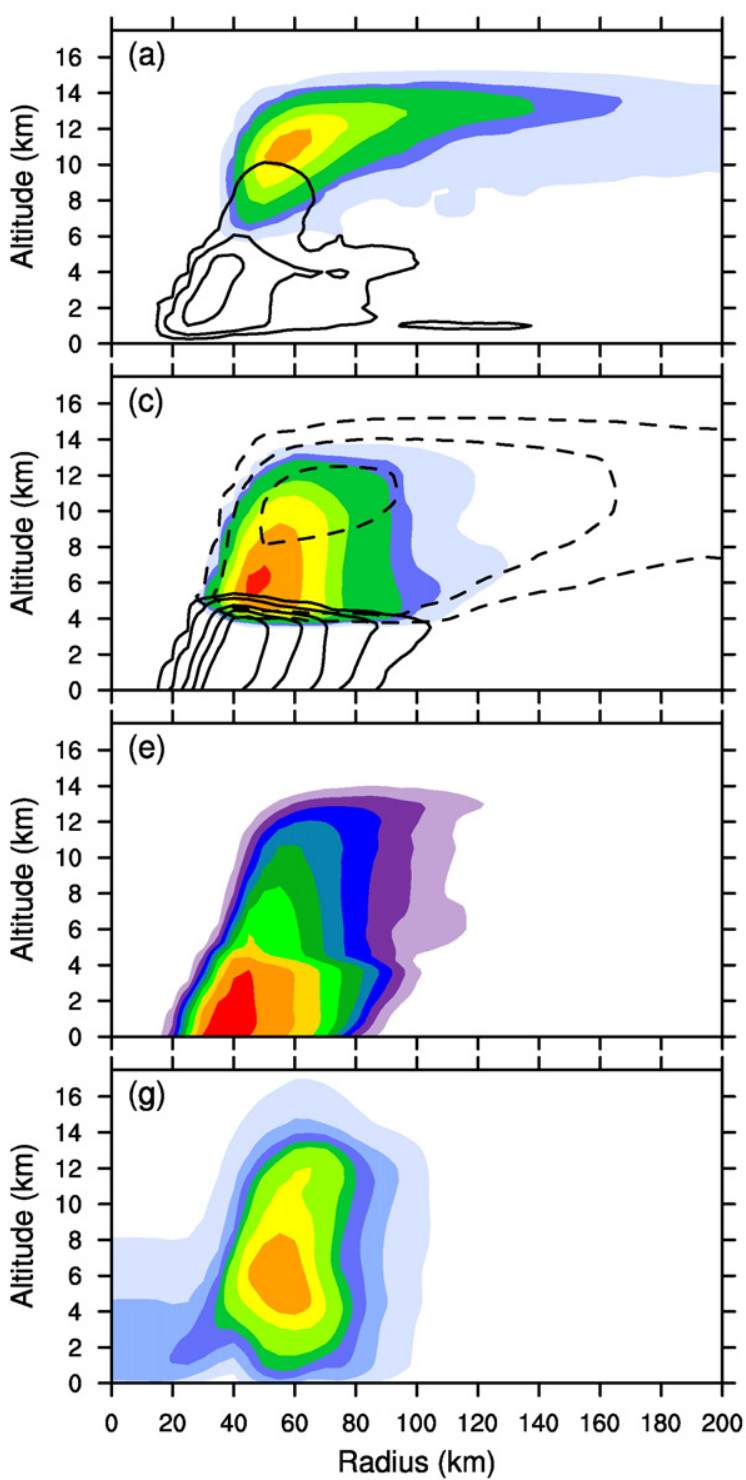

SGFS

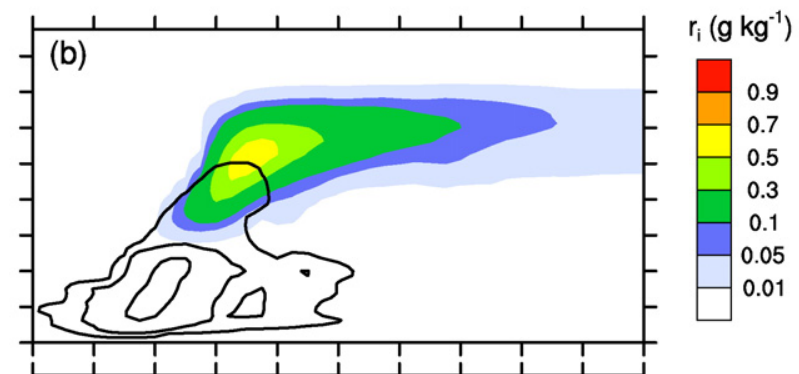

(d)
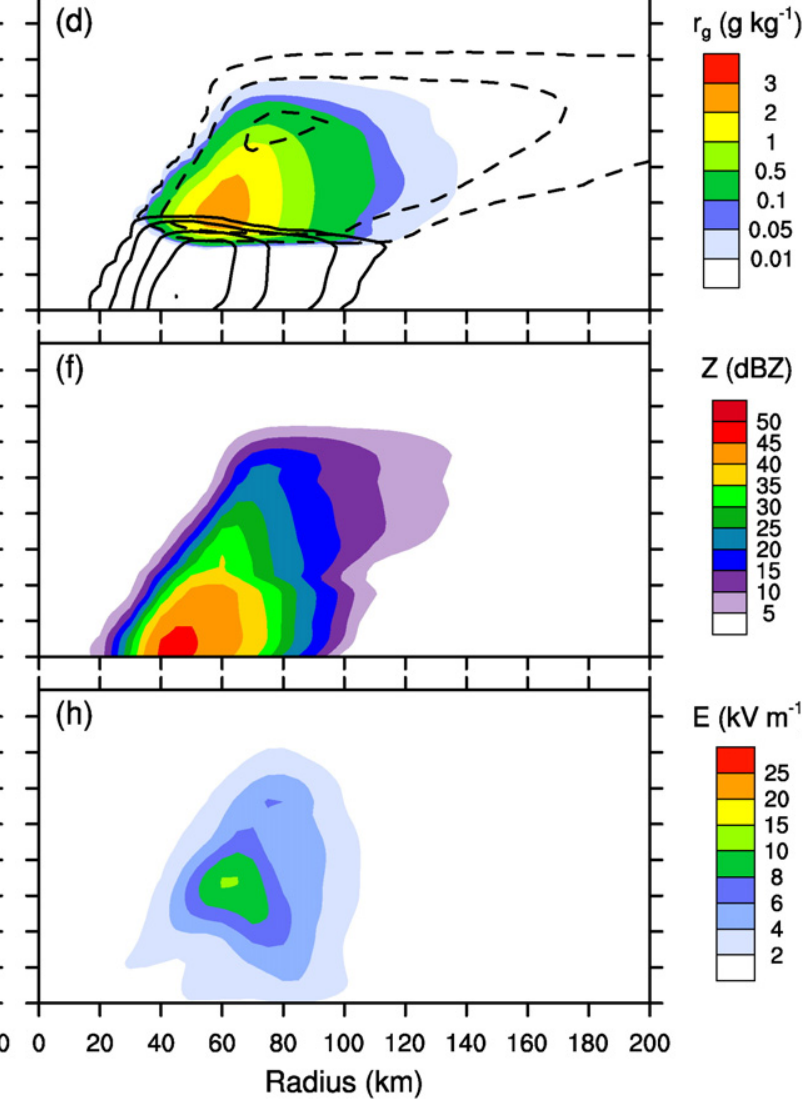

$E\left(\mathrm{kV} \mathrm{m}^{-1}\right)$

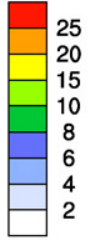

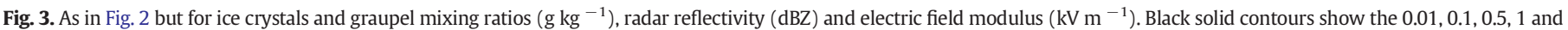
$1.5 \mathrm{~g} \mathrm{~kg}^{-1}$ cloud droplet and rain mixing ratios for $1^{\text {st }}$ and $2^{\text {nd }}$ lines, respectively. The black dashed contours in the $2^{\text {nd }}$ line show the $0.01,0.1$ and $0.5 \mathrm{~g}$ kg ${ }^{-1}$ snow mixing ratio.

run $\left(1.6 \mathrm{~g} \mathrm{~kg}^{-1}\right.$ vs. $1.0 \mathrm{~g} \mathrm{~kg}^{-1}$ for $r_{i}, 6 \mathrm{~g} \mathrm{~kg}^{-1} \mathrm{vs} .4 .5 \mathrm{~g} \mathrm{~kg}^{-1}$ for $r_{r}$, and $9 \mathrm{~g} \mathrm{~kg}^{-1}$ vs. $7 \mathrm{~g} \mathrm{~kg}^{-1}$ for $r_{\mathrm{g}}$ ). However, the $2 \%$ contour of graupel mixing ratio does not exceed $2.5 \mathrm{~g} \mathrm{~kg}^{-1}$ in CTRL and $3 \mathrm{~g} \mathrm{~kg}^{-1}$ in SGFS. It is important to note that the cloud droplet mixing ratio is larger above $6 \mathrm{~km}$ altitude in the CTRL run (Fig. 5c). This difference is crucial for cloud electrification since the charge separated per collision is highly dependent on the liquid water content (Saunders et al., 1991). Cloud ice can be found at higher altitude in the CTRL run, in agreement with the higher updrafts encountered in this simulation.

\subsection{Temporal evolution of the storm variables}

However, these differences between the CTRL and the SGFS simulations were not specific to $84 \mathrm{~h}$ of simulation. Fig. 6 shows Hovmoller diagrams of the azimuthally-averaged radar reflectivity at $1.2 \mathrm{~km}$ altitude, vertical velocity at $6 \mathrm{~km}$ altitude and maximum electric field modulus per column for the CTRL and the SGFS simulations. In the CTRL simulation, the $0.5 \mathrm{~m} \mathrm{~s}^{-1}$ contour of $w$ at $6 \mathrm{~km}$ altitude (Fig. 6b) is between 25 and $60 \mathrm{~km}$ from the storm center. Intermittent
$2.5 \mathrm{~m} \mathrm{~s}^{-1}$ values mainly occur around $50 \mathrm{~km}$ from the storm center. The SGFS simulation shows a different behavior of $w$ at $6 \mathrm{~km}$ altitude (Fig. 6f) throughout the simulation. The $0.5 \mathrm{~m} \mathrm{~s}^{-1}$ contour is discontinuous and is centered around $55 \mathrm{~km}$ from the storm center, i.e. $5 \mathrm{~km}$ farther from the storm center than in the CTRL simulation. Moreover, only two regions of $w>1.5 \mathrm{~m} \mathrm{~s}^{-1}$ are seen, at 67 and $88 \mathrm{~h}$, while this situation is much more frequent during the CTRL simulation.

Marked differences are also visible in the $Z$ time-radius diagram (Fig. 6a and e). In the CTRL simulation, the $40 \mathrm{dBZ}$ envelope at $1.2 \mathrm{~km}$ altitude is continuous between 60 and $96 \mathrm{~h}$, and centered around $45 \mathrm{~km}$ from the storm center. In the SGFS simulation, this same envelope is fragmented and is shifted toward a higher radius from the storm center. This translates into strong differences in maximum electric field modulus per column (Fig. $6 \mathrm{c}$ and g) throughout the simulation. The maximum value per column of the azimuthally averaged electric field modulus exceeds $15 \mathrm{kV} \mathrm{m}^{-1}$ over a large region (between 25 and $50 \mathrm{~km}$ in radius) in the CTRL simulation. In the SGFS simulation, almost the whole region between 0 and $120 \mathrm{~km}$ from the storm center has maximum value of azimuthally 

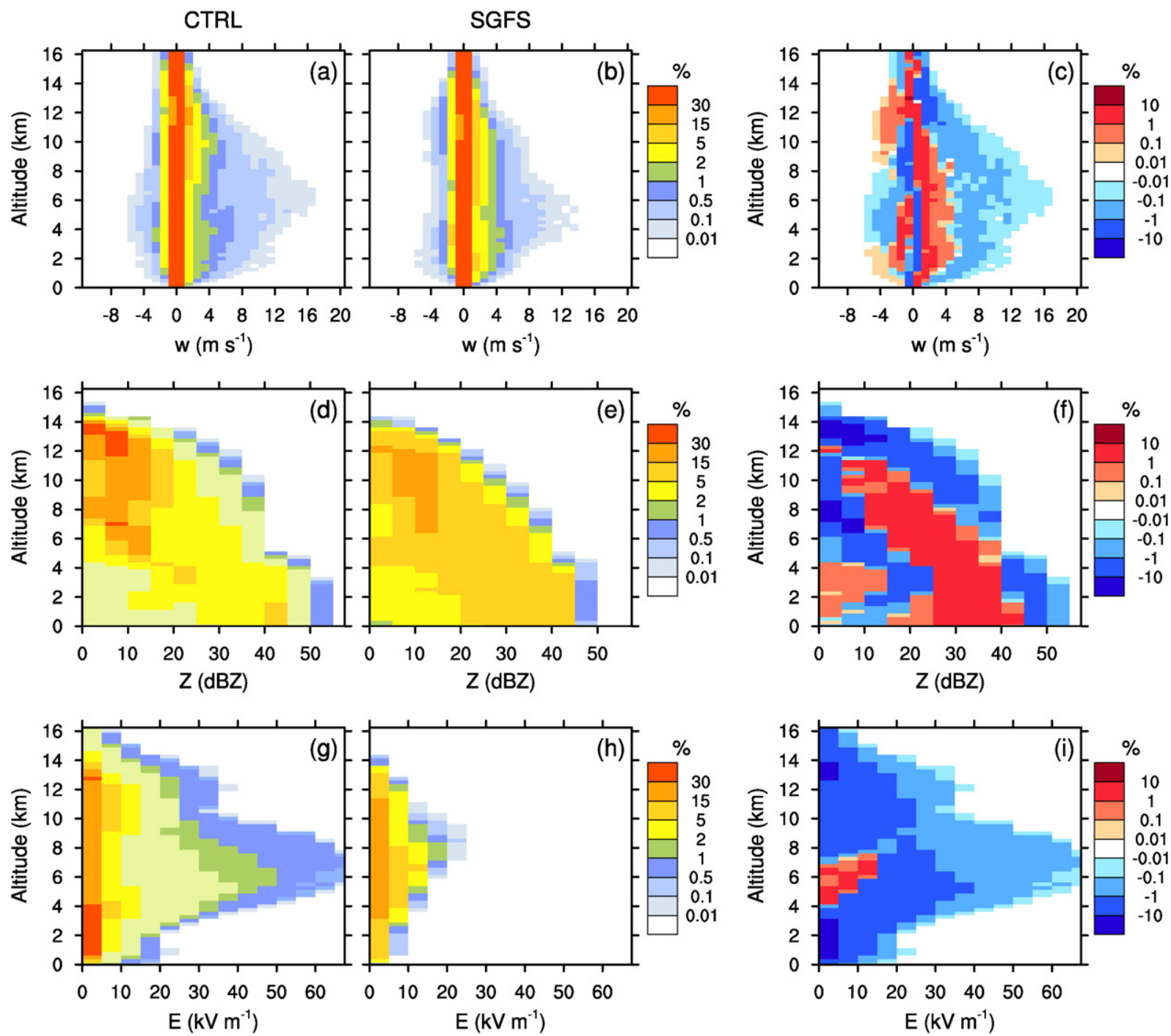

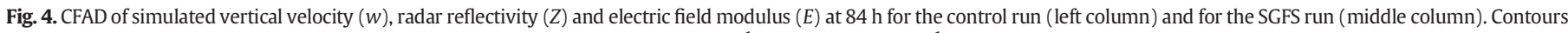

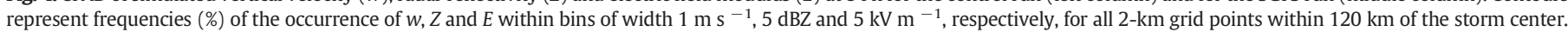
Difference plotted (right column) is the CFAD of $w, Z$ and $E$ for the control run minus the CFAD of $w, Z$ and $E$ for the run with lower graupel fall speed.

averaged electric field modulus higher than $1 \mathrm{kV} \mathrm{m}^{-1}$. It barely reaches $10 \mathrm{kV} \mathrm{m}^{-1}$ three times ( 74,84 and $89 \mathrm{~h}$ ) over the 48 -h period during which the electrical scheme is activated.

Although the dynamical and microphysical variables do not show very marked differences, the differences in electrical variables are extremely strong. The temporal evolution of the total flash rate (Fig. 6d and h) illustrates this pronounced difference. In the CTRL simulation, the total flash rate varies between 0 and $84 \mathrm{fl}$. min ${ }^{-1}$ with a mean value of $2.4 \mathrm{fl}$ min $^{-1}$. In contrast, in the SGFS simulation, the total flash rate is close to 0 throughout the simulation except for a few flashes at 49 and $74 \mathrm{~h}$. Only a few numerical experiments of electrified tropical storms are reported in the literature. In their simulation of an electrified idealized hurricane-like vortex, Fierro et al. (2007) found an IC flash rate varying between 400 and 1000 flashes per minute. They acknowledged these values were unrealistically high for flash rates in hurricanes. Fierro and Reisner (2011) simulated the rapid intensification phase of Rita to study relationships between lightning activity and eyewall convection. While the simulated flash rate for the $4 \mathrm{~km}$ run was comparable to observations, the $2-\mathrm{km}$ run flash rate was 100 times higher. This scale dependency could be explained by the relatively simple representation of lightning propagation, which did not take the stochastic branching into account as Mansell et al. (2002) and Barthe et al. (2012) did. Nevertheless, it is difficult to compare the total flash rate obtained in this study with flash rates encountered in the literature or with observed flash rates: we performed an idealized simulation of a tropical cyclone, and few observations of the total flash rate (IC + CG) are available over the ocean.

\subsection{Electrical signature}

The electrical signature of the cyclone was investigated at 84 h. Fig. 7 shows west-east vertical cross sections through the storm center of the mixing ratios and charge densities of the 5 hydrometeor categories. For both CTRL and SGFS, the $0.01 \mathrm{~g} \mathrm{~kg}^{-1}$ mixing ratio for cloud droplets reaches $10 \mathrm{~km}$ altitude. However, in the CTRL simulation, the cloud droplet mixing ratio is $0.1 \mathrm{~g} \mathrm{~kg}^{-1}$ at $8 \mathrm{~km}$ altitude while in the SGFS simulation, mixing ratios higher than $0.1 \mathrm{~g} \mathrm{~kg}^{-1}$ are concentrated below $6 \mathrm{~km}$ altitude. The presence of cloud droplets and more or less heavily rimed ice particles in the charging zone (between 0 and $-20^{\circ} \mathrm{C}$ ) permits cloud electrification via the non-inductive process (Fig. 8).

Graupel is mainly negatively charged in both simulations with a maximum of $-3 \mathrm{nC} \mathrm{m}{ }^{-3}$ in CTRL and $-1 \mathrm{nC} \mathrm{m}^{-3}$ in SGFS. This is 
CTRL
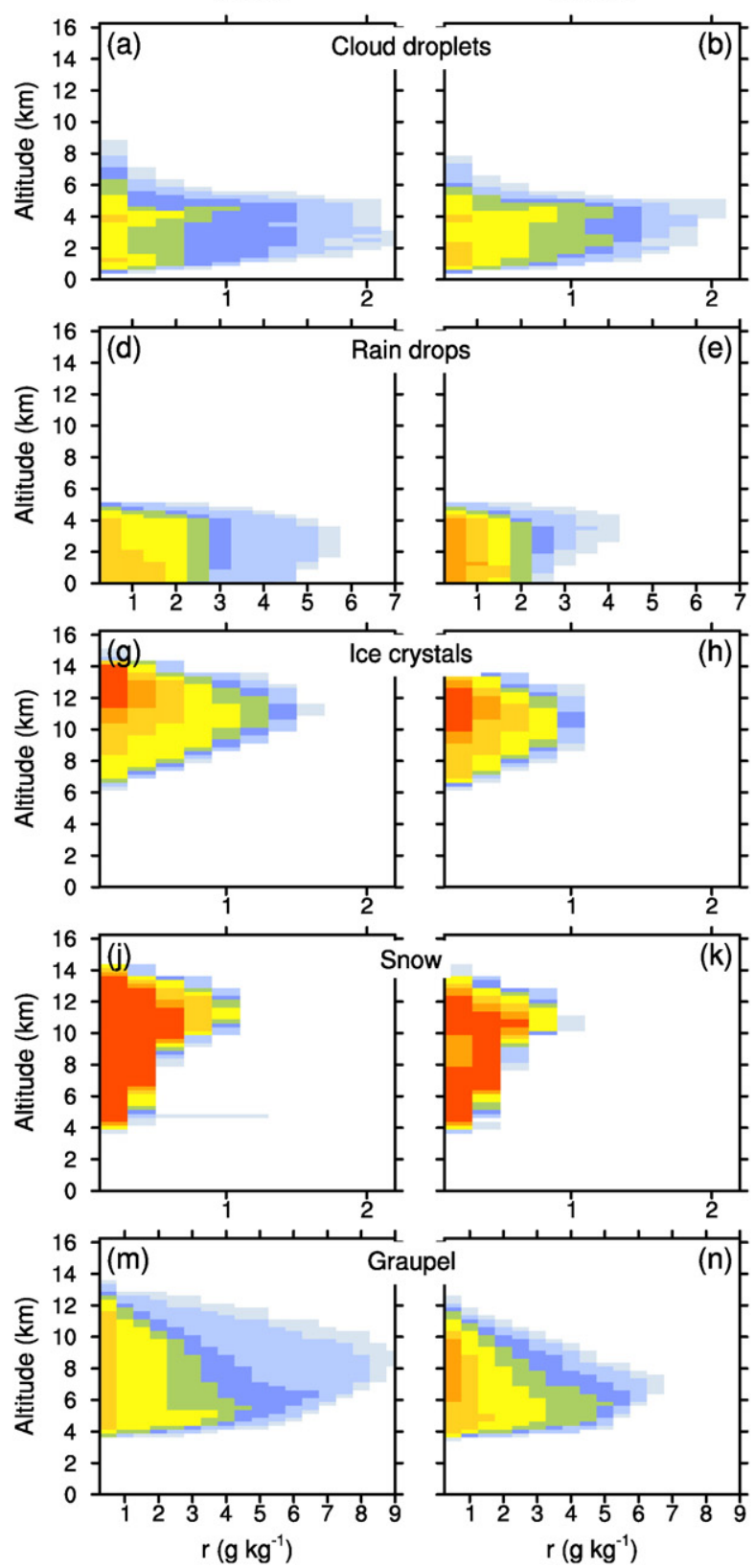
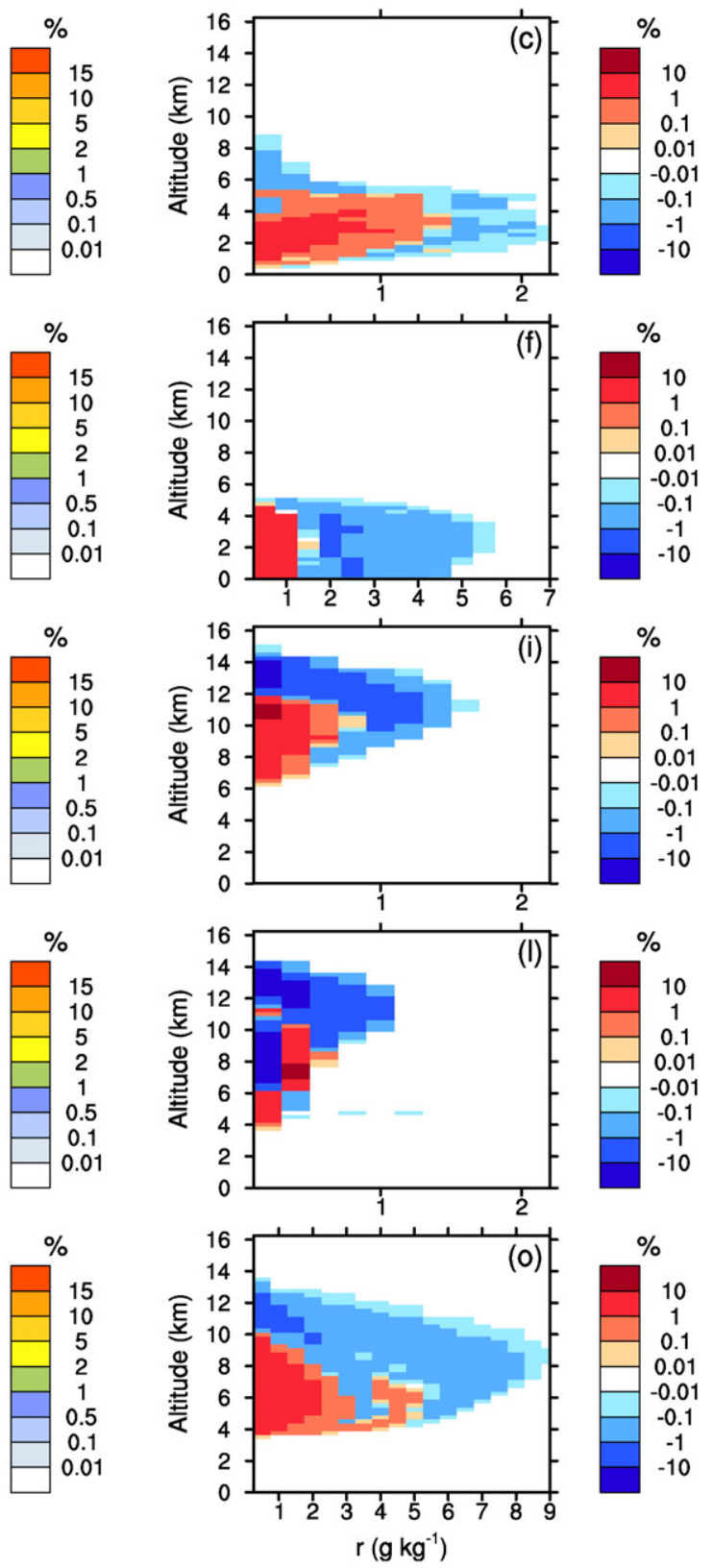

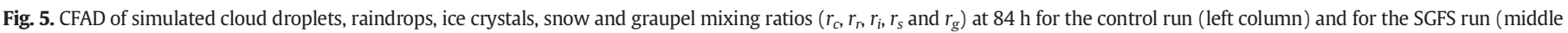

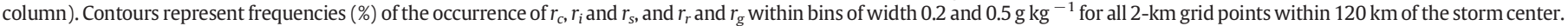
Difference plotted (right column) is the CFAD of $r_{c}, r_{r}, r_{i}, r_{s}$ and $r_{g}$ for the control run minus the CFAD of $r_{c}, r_{r}, r_{i}, r_{s}$ and $r_{g}$ for the run with lower graupel fall speed.

due to a negative non-inductive charging rate (Fig. 8c-d) between 4 and $8 \mathrm{~km}$ altitude. In Figure 7 in Saunders et al. (1991), it corresponds to the region with $T>-20^{\circ} \mathrm{C}$ and low effective water content (EWC less than $0.22 \mathrm{~g} \mathrm{~m}^{-3}$ ). Just above the $0^{\circ} \mathrm{C}$ isotherm, the non-inductive charging rate can be positive (Fig. $8 \mathrm{c}-\mathrm{d}$ ) because of higher values of $E W C$ at this altitude (Fig. 7a-b). However, positive charging of graupel occurs close to the $0^{\circ} \mathrm{C}$ isotherm, where relatively low EWC $\left(\sim 0.2-0.3 \mathrm{~g} \mathrm{~m}^{-3}\right)$ are required to positively charge the largest particles. It can also appear at high altitude, above the $-20{ }^{\circ} \mathrm{C}$ isotherm, due to the presence of the anomalous positive charging zone in Saunders's diagram. Although the non-inductive charging rate is mainly negative in this cross-section, the inductive charging rate has both positive and negative values depending on the sign of the vertical component of the electric field.
Fig. 9a shows the temporal evolution of the mean non-inductive charging rate for the CTRL and SGFS simulations. For positive charging, the mean non-inductive charging rate is in the ranges of 1.7$4.5 \mathrm{pC} \mathrm{m}{ }^{-3} \mathrm{~s}^{-1}$ and $0.3-0.9 \mathrm{pC} \mathrm{m}{ }^{-3} \mathrm{~s}^{-1}$ for the CTRL and SGFS storms, respectively. The negative charging is higher with mean values between -2.5 and $-4.9 \mathrm{pC} \mathrm{m}^{-3} \mathrm{~s}^{-1}$ and -0.7 and $-1.7 \mathrm{pC} \mathrm{m}-3 \mathrm{~s}^{-1}$ for the CTRL and SGFS storms, respectively. Thus Fig. 9a confirms that both the mean positive and negative non-inductive charging rates are higher in the CTRL storm than in the SGFS storm. In contrast, Fig. 9b shows that the volume where non-inductive charging occurs is slightly higher in the SGFS storm. It is also clear from Fig. 9 that negative non-inductive charging predominates over positive non-inductive charging in this storm. 

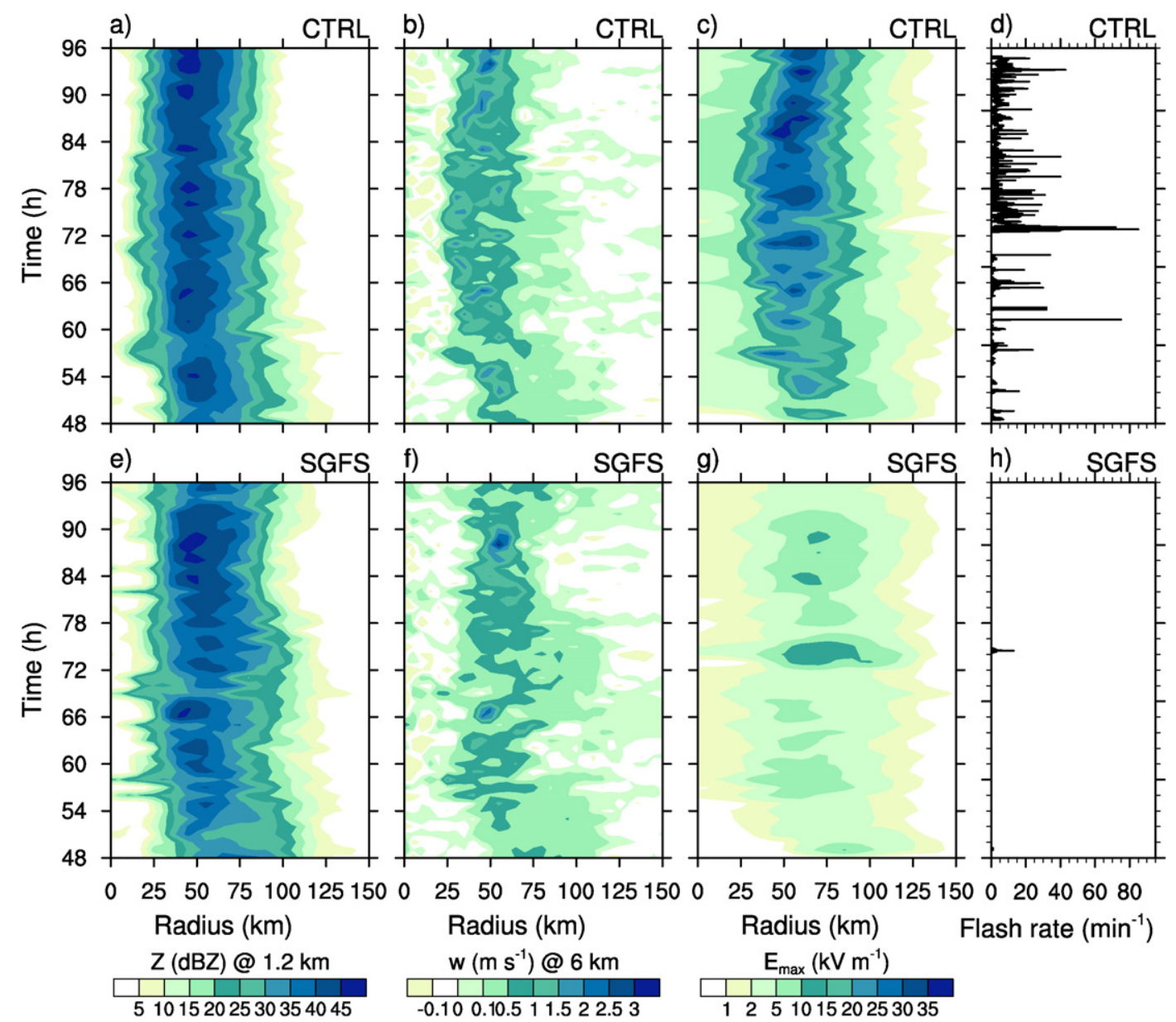

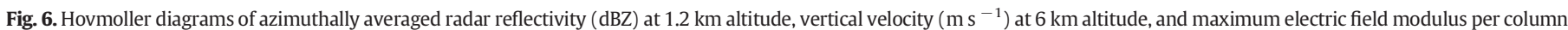
$\left(\mathrm{kV} \mathrm{m}^{-1}\right)$, and temporal evolution of the flash rate (fl. $\mathrm{min}^{-1}$ ) for the CTRL (top) and SGFS (bottom) simulations.

In the CTRL simulation, rain charge density displayed alternating positive and negative charge regions along the horizontal (Fig. 7c-d). The rain charge was mainly a product of graupel melting since the positive and negative charges carried by rain were located just below the positive and negative charges carried by graupel. However, the positive charge at the inner edge of the eyewall was due rather to warm processes associated with positive cloud droplets (autoconversion of cloud droplets, accretion of cloud droplets by raindrops). The rain charge density in the SGFS simulation exhibited much less variability (Fig. 7d). It was mainly negative and associated with graupel melting.

Ice crystals and snow charge density showed the same pattern with a positive charge region below a negative charge region. As for the other hydrometeor categories, the eastern eyewall was the most electrically active due to the more vigorous updraft encountered in this region (Fig. $8 \mathrm{~g}-\mathrm{h}$ ). This can also be seen on the total charge structure (Fig. 8a-b).

The total charge density was higher in the eastern eyewall in both simulations, and the poles of charges were shifted to higher altitudes compared to the poles of charges in the western eyewall. The positive charge density found in the central eye was mainly due to cloud droplet evaporation at the inner edge of the eyewall, releasing positive small ions. The charge structure was more or less complex depending on the location in the cyclone. Inside the eye, only positive small ions were found. In the eyewall, the charge structure was mainly tripolar with a positive charge surrounded by two negative charge layers. Moving away from the storm center, the charge structure became more complex. The charge density was lower because of charge advection that prevailed over local charge separation concentrated in the eyewall region (Fig. $8 \mathrm{c}-\mathrm{d}$ ), where the most intense updrafts were found (Fig. 8g-h). The charge structure simulated here is more complex than the one reported by Black and Hallett (1999). From aircraft data obtained during penetration of hurricanes Claudette and Tina, Black and Hallett (1999) suggested that the negative over positive dipole dominated in the hurricane eyewall above $-13^{\circ} \mathrm{C}$. They hypothesized that the majority of large particles acquired negative charge, which is consistent with the negatively charged graupel simulated here (Fig. $7 \mathrm{i}-\mathrm{j}$ ). The charge structure of the idealized hurricane simulated by Fierro et al. (2007) exhibited a normal tripole charge structure in the eyewall. However, it must be noted that the gross charge structure is very sensitive to the non-inductive parameterization selected in the model (Helsdon et al., 2001; Altaratz et al., 2005; Mansell et al., 2005; Fierro et al., 2006; Kuhlman et al., 2006; Barthe and Pinty, 2007; Tsenova et al., 2013). This could partly explain why the charge structure simulated here is different from the normal tripole charge structure of the idealized hurricane simulated by Fierro et al. (2007), who used the Saunders and Peck's (1998) parameterization for non-inductive charging. The tripole structure (Williams, 1989) has long been known to be the ideal structure that needs to be retrieved in electrified storm simulations. However, if the non-inductive mechanism can explain this tripolar charge structure, it must be kept in mind that secondary charging processes may take part in cloud electrification. Moreover, Bruning et al. (2014) pointed out that the environmental thermodynamic and aerosol controls on the supercooled water content and thus on the non-inductive charging is also a key issue in the charge structure establishment, and that charge structure varies continuously. The multidimensional structure of the flow is also signaled as a key factor by Bruning et al. (2014) in generating inverted or more complex 


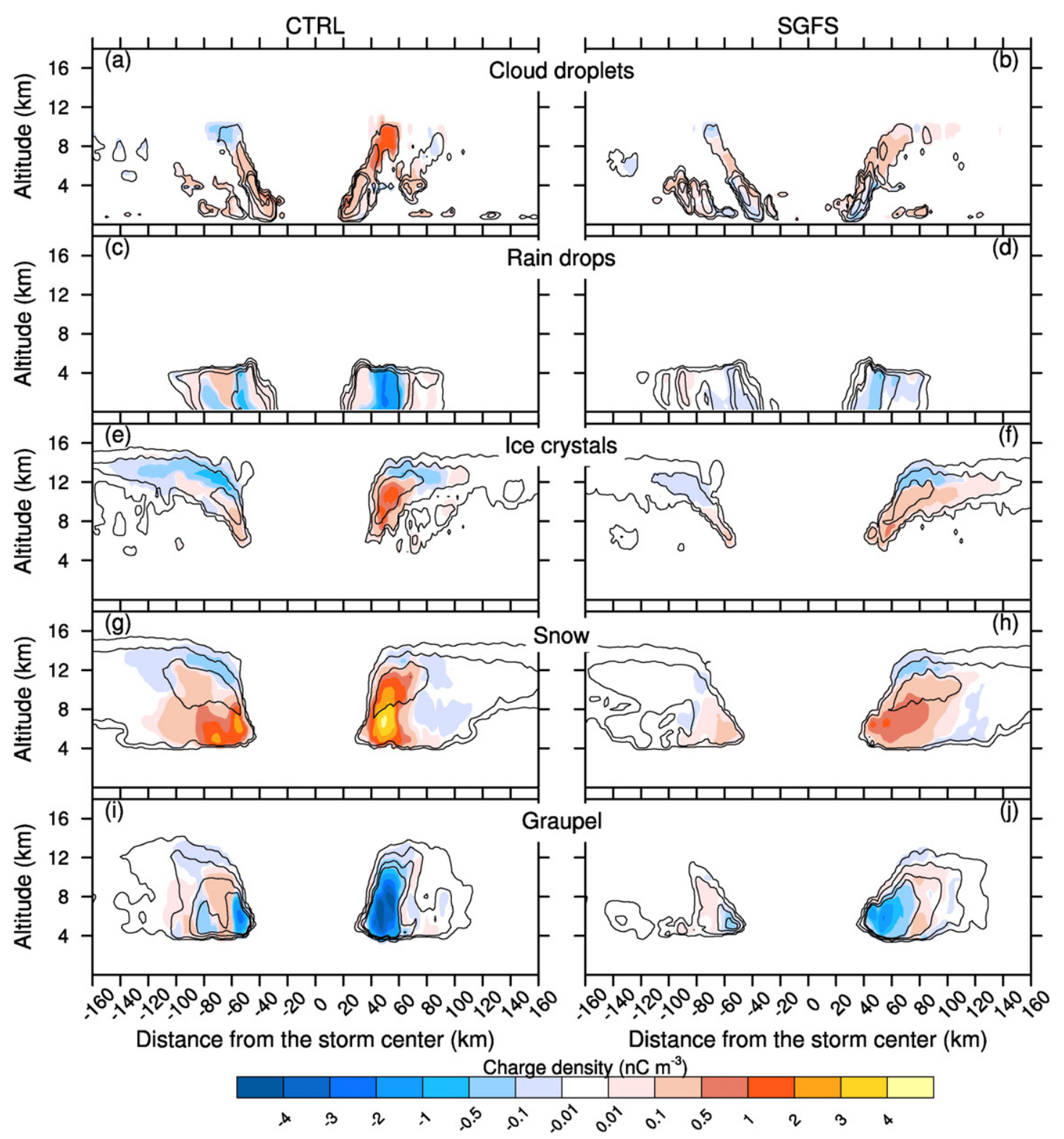

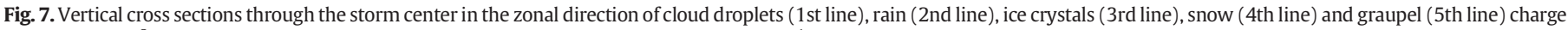

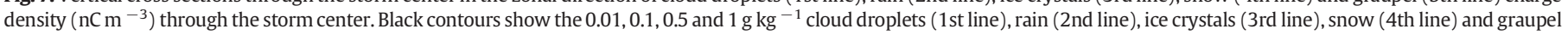
(5th line) mixing ratios.

structures. The relatively weak convection encountered in the eyewall of tropical cyclones confines supercooled water at low altitude. Therefore, the mixed phase region where electrification can occurr is confined at the inner edge of the eyewall (Cecil and Zipser, 2002), in a thin layer. In the Saunders et al. (1991) diagram, it corresponds to the region with low effective water content and warm temperatures, leading to a positive layer embedded into a upper negative and a lower negative layers in the region of the updraft core. If the liquid water content is very low (at the outer edge of the eyewall for example), a dipolar structure should be expected following the Saunders's diagram. In addition, the three-dimensional flow of the tropical cyclone (primary and secondary circulations) leads to a radial and tangential advection of the charges.

The resulting electric field modulus was higher in the CTRL simulation (Fig. 8e-f) as already seen in Figs. 2, 4 and 6. The electric field modulus reached $50 \mathrm{kV} \mathrm{m}^{-1}$ between 6 and $8 \mathrm{~km}$ altitude in the CTRL simulation. Fig. 10 shows that lightning flashes in the CTRL simulation are triggered at two preferred altitudes: 7-8 km and $12 \mathrm{~km}$, which correspond to the two maxima in Fig. 4. These two locations of flash triggering are associated with triggering electric field values of 70 and $40 \mathrm{kV} \mathrm{m}^{-1}$ (Fig. 10b). As the triggering electric field decreases with increasing height (Marshall et al., 1995), a lower electric field is required at high altitude to trigger lightning flashes. In their simulation of a hurricane based on the environment of hurricane Isaac (2012), (Fierro et al., 2015) found 3 distinct layers in which lightning flashes are preferentially triggered: 10.5, 7 and $9 \mathrm{~km}$ altitude. In the SGFS simulation, the flashes were mainly triggered at 8-9 km altitude with an electric field of about $70 \mathrm{kV} \mathrm{m}^{-1}$. At $84 \mathrm{~h}$, some pockets of $5 \mathrm{kV} \mathrm{m}^{-1}$ electric field modulus were scattered in the eyewall of the SGFS simulation (Fig. 8).

\section{Discussion and conclusion}

A change in the graupel characteristics has a significant impact on the cyclone intensity and structure but not on the track. The most dramatic effect can be seen on the total flash rate computed by the model. Reducing the graupel fall speed almost suppresses the lightning activity for this 

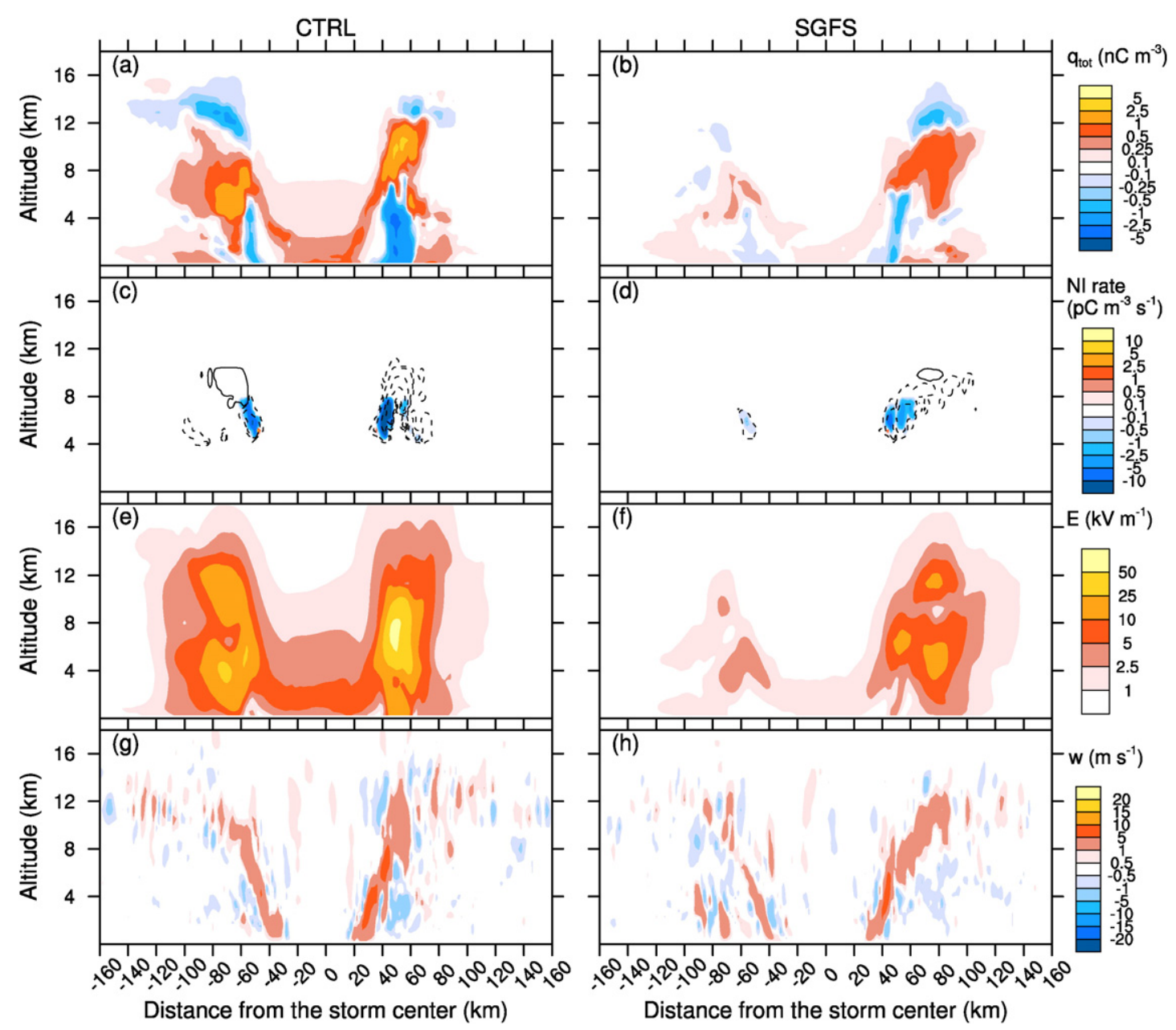

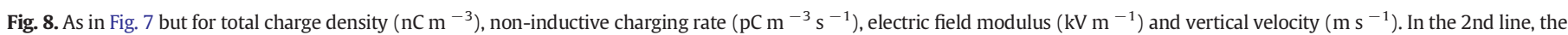
dashed and solid contours show the $-10,-5,-1$ and $-0.1 \mathrm{pC} \mathrm{m}^{-3} \mathrm{~s}^{-1}$ and the $0.1,1,5$ and $10 \mathrm{pC} \mathrm{m}^{-3} \mathrm{~s}^{-1}$ inductive charging rate, respectively.

idealized tropical cyclone. Results from these simulations show that modifying the graupel fall speed can act at different levels.

(i) The coefficients $a, b, c$ and $d$ of the mass-diameter and velocitydiameter relationships are part of the mass transfer equations. Modifying these coefficients so that the graupel fall speed is lowered reduces the mass transfers. Hydrometeors are less available for phase change and the latent heat release is reduced. Air buoyancy is then reduced, which decreases the updraft strength. A modification of the graupel characteristics acts on the whole cyclonic circulation through thermodynamic and dynamical processes (McFarquhar et al., 2006).

(ii) As for mass transfers, local charge separation and charge transfers associated with microphysical processes also depend on the coefficients $a, b, c$ and $d$. Following Saunders et al. (1991), the charge separated during an elastic collision between two ice particles is $\Delta q=B D^{m}(\Delta v)^{n} q$ (in $\mathrm{fC}$ ). $D(\mathrm{~m})$ is the diameter of the smallest particle, $\Delta v\left(\mathrm{~m} \mathrm{~s}^{-1}\right)$ is the relative impact speed, and $q(\mathrm{fC})$ is the amount of charge transferred per collision. The coefficients $m, n$ and $B$ depend on the size of the smallest particle and on the sign of the charge received by the largest particle. Following Saunders et al. (1991), the coefficient $n$ is 2.5 or 2.8 , depending on the sign of the charge transferred. This means that a relatively small modification of the graupel fall speed can result in a large modification of the charge separated per collision (Fig. 9). (iii) When the graupel fall speed is decreased, graupel can be spread horizontally over a broader area (Figs. 3 and 7). This can increase the volume where charge separation by non-inductive charging can occur (Fig. 9b). But graupel is less available in the eyewall for charge separation. In this case study, the volume effect could not counterbalance the lower charging rate per grid point in the SGFS simulation (Fig. 9).

(iv) More pronounced updraft tilting result in pockets of charge not being directly superposed and thus in a reduction of the electric field (Figs. 2 and 3). In addition, particles are advected tangentially away from the updrafts, which reduces both the horizontal and vertical gradient of charges (Black and Hallett, 1999). Graupel particles are heavier than cloud ice, but are found at lower altitudes and are thus exposed to higher tangential velocities. The net effect of the differential tangential advection on the dipole alignment is thus not trivial.

Since cloud electrification and lightning triggering and propagation are threshold processes, the non-occurrence of lightning flashes in a tropical cyclone does not necessarily mean that the system is not electrified. It rather means that the updraft strength necessary for charge separation is not reached, or that the electric field in the cloud is lower than the field needed for flash triggering. Whatever the noninductive parameterization (Takahashi, 1978; Saunders et al., 1991; Saunders and Peck, 1998; Tsenova et al., 2013) implemented in the 

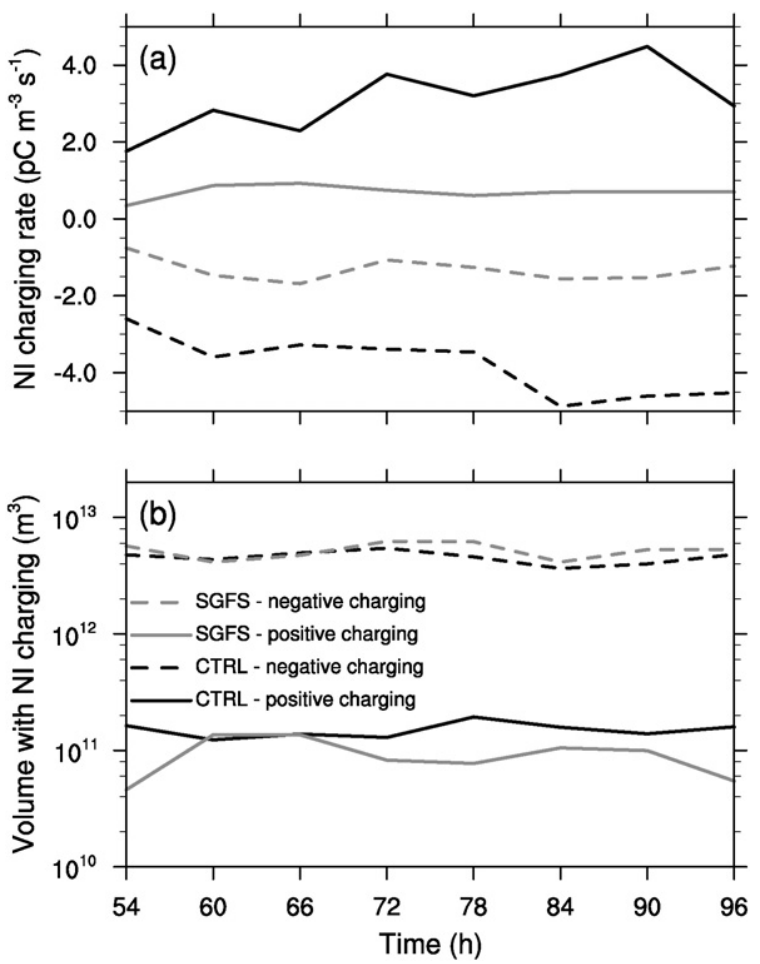

Fig. 9. Temporal evolution of (a) the non-inductive charging rate averaged per grid-point ( $\mathrm{pC} \mathrm{m}^{-3} \mathrm{~s}^{-1}$ ) and (b) the volume where non-inductive charging occurs $\left(\mathrm{m}^{3}\right)$ for the control run (solid lines) and for the run performed with slower graupel fall speed (dashed lines). The black and gray lines represent positive and negative non-inductive charging, respectively.

CELLS scheme, the charge separated per collision is a function of the relative fall speed between graupel and ice crystal. Thus, if the graupel fall speed is equal to the ice crystal fall speed, the charge exchanged per collision is zero, and the cloud is not getting electrified. However, in this study, it is shown that even if the graupel fall speed is not reduced to the ice crystal fall speed, the cloud is getting electrified but the storm is not producing a significant lightning activity (Fig. 6h). Therefore, for this particular storm and for this particular non-inductive parameterization (Saunders et al., 1991), a threshold value for the graupel fall speed is almost reached. However, this value should be different for another kind of storm with more intense updrafts and a more developed mixed phase region. Indeed, the low charging rate per collision could be partly compensated by a higher number of graupel-ice crystal collisions efficient for charge separation. It should also change if another parameterization of the non-inductive process was used. In the Saunders's parameterizations, the charge separated per collision is linked to the graupel fall speed by a power law relation while in the Takahashi's parameterization a linear relation is used. If the Takahashi's parameterization was used, the same change in the graupel fall speed would have a smaller impact on the amount of charge separated per collision. Then, the graupel fall speed threshold value leading to an absence of electrification and/or lightning is probably lower for Takahashi's than for Saunders's parameterization.

The main advantage of performing idealized simulations of convective systems is that they are free from the impact of the environment, which makes the study of physical processes easier. This study allowed us to underline some key physical processes in a tropical cyclone-like vortex, and will serve as a basis for future studies of tropical storms electrification with the Meso-NH model. However, several limitations are associated to this idealized simulation. First, direct comparison with observation is impossible. Secondly, the importance of vertical wind shear on the azimuthal asymmetry of convection and lightning pointed out by Corbosiero and Molinari (2003) is not considered in this study.
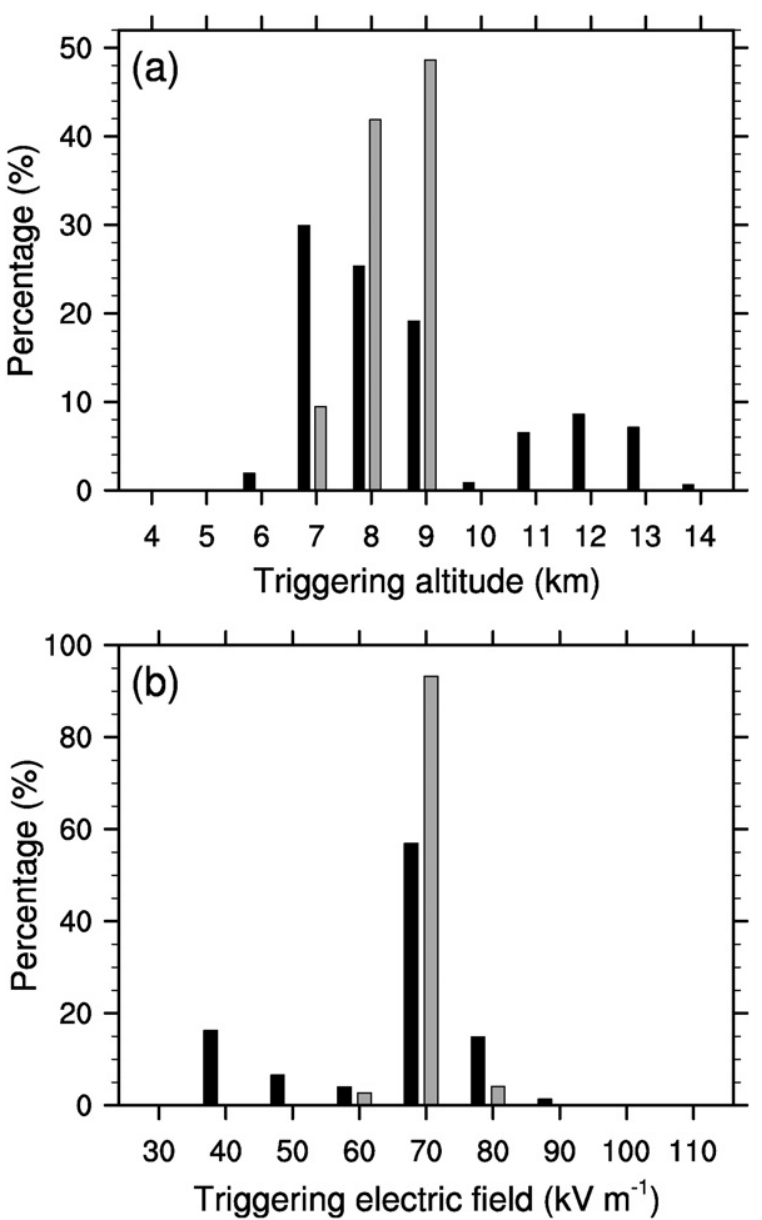

Fig. 10. Histograms of the (a) triggering altitude (km) and (b) triggering electric field $\left(\mathrm{kV} \mathrm{m}^{-1}\right)$ for the CTRL run (black bars) and for the SGFS run (gray bars).

Another drawback of the simulation presented here is the use of a 1moment scheme that does not allow the Hallet-Mossop process (Hallett and Mossop, 1974) to be treated. This mechanism is hypothesized to be significantly active to generate a supply of ice crystals (Black and Hallett, 1986). Moreover, Rosenfeld et al. (2012) recommended taking the aerosol effects on microphysics and thermodynamics into account to advance in forecasting the intensities of tropical cyclones. Up to now, only few numerical studies have investigated the aerosol effect on the electrical state of thunderstorms. Tan et al. (2016) have recently shown that the effect of aerosols concentration on charge separation is non-linear, while Mansell and Ziegler (2013) found that a greater cloud condensation nuclei concentration tends to lead to greater lightning activity, but with a large sensitivity to ice multiplication. Khain et al. (2008) underlined the complex interactions between aerosol, tropical cyclone structure and potential lightning activity. In addition, an increasing number of observational studies show that the lightning activity may be impacted by aerosols from different origins (Lyons et al., 1998; Altaratz et al., 2010; Wang et al., 2011; Yuan et al., 2011; Tan et al., 2015; Stolz et al., 2015; Proestakis et al., 2016), among others.

In this context, the next step will be the simulation of a recent tropical cyclone in the South-West Indian Ocean initialized with meteorological analysis. This future study will combine a 2-moment microphysical scheme with a 3D budget of aerosols (Vié et al., 2016) along with the CELLS electrical scheme (Barthe et al., 2012). This model configuration will allow us to study the dynamical, microphysical and electrical processes involved in rapid intensification phases. 


\section{Acknowledgments}

The French program LEFE/IMAGO of INSU/CNRS supported the present study. Computer resources were allocated by GENCI (project 6660). Part of this work was done during the PhDs of T. Hoarau and C. Bovalo, who were financially supported by Reunion Island Regional Council and the European Union Council.

\section{References}

Abarca, S.F., Corbosiero, K.L., Vollaro, D., 2011. The World Wide Lightning Location Network and convective activity in tropical cyclones. Mon. Weather Rev. 139, 175-191.

Altaratz, O., Reisin, T., Levin, Z., 2005. Simulation of the electrification of winter thunderclouds using the three-dimensional Regional Atmospheric Modeling Systems (RAMS) model: single cloud simulations. J. Geophys. Res. 110. http://dx.doi.org/10.1029/ 2004JD005616.

Altaratz, O., Koren, I., Yair, Y., Price, C., 2010. Lightning response to smoke from amazonian fires. Geophys. Res. Lett. 37. http://dx.doi.org/10.1029/2010GL042679.

Barthe, C., Pinty, J.P., 2007. Simulation of electrified storms with comparisons of the charge structure and lightning flash efficiency. J. Geophys. Res. 112. http://dx.doi. org/10.1029/2006JD008241.

Barthe, C., Chong, M., Pinty, J.P., Bovalo, C., Escobar, J., 2012. CELLS v1.0: updated and parallelized version of an electrical scheme to simulate multiple electrified clouds and flashes over large domains. Geosci. Model Dev. 5, 167-184. http://dx.doi.org/ 10.5194/gmd-5-167-2012.

Bechtold, P., Bazile, E., Guichard, F., Mascart, P., Richard, E., 2001. A mass-flux convection scheme for regional and global models. Quart. J. Roy. Meteor. Soc. 127, 869-886.

Black, R.A., Hallett, J., 1986. Observations of the distribution of ice in hurricanes. J. Atmos. Sci. $43,802-822$

Black, R.A., Hallett, J., 1999. Electrification of the hurricanes. J. Atmos. Sci. 56, 2004-2028

Black, M.L., Burpee, R.W., Marks Jr., F.D., 1996. Vertical motions characteristics of tropical cyclones determined with airborne doppler radial velocities. J. Atmos. Sci. 53, 1887-1909.

Bougeault, P., Lacarrère, P., 1989. Parameterization of orography-induced turbulence in a meso-beta-scale model. Mon. Weather Rev. 117, 1872-1890.

Bovalo, C., Barthe, C., Yu, N., Bègue, N., 2014. Lightning activity in tropical cyclones in the South West Indian Ocean. J. Geophys. Res. Atmos. 119. http://dx.doi.org/10.1002/ 2014JD021651.

Brooks, I.M., Saunders, C.P.R., Mitzeva, R.P., Peck, S.L., 1997. The effect on thunderstorm charging of the rate of rime accretion by graupel. Atmos. Res. 43, 277-295.

Bruning, E.C., Weiss, S.A., Calhoun, K.M., 2014. Continuous variability in thunderstorm primary electrification and an evaluation of inverted-polarity terminology. Atmos. Res. 135-136, 274-284. http://dx.doi.org/10.1016/j.atmosres.2012.10.009.

Cecil, D.J., Zipser, E.J., 1999. Relationships between tropical cyclone intensity and satellitebased indicators of inner core convection: $85-\mathrm{GHz}$ ice-scattering signature and lightning. Mon. Weather Rev. 127, 103-123.

Cecil, D.J., Zipser, E.J., 2002. Reflectivity, ice scattering, and lightning characteristics of hurricane eyewalls and rainbands. Part II: Intercomparison of observations. Mon. Weather Rev. 130, 785-801

Cecil, D.J., Zipser, E.J., Nesbitt, S.W., 2002. Reflectivity, ice scattering, and lightning characteristics of hurricane eyewalls and rainbands. Part I: Quantitative description. Mon. Weather Rev. 130, 769-784.

Corbosiero, K.L., Molinari, J., 2003. The relationship between storm motion, vertical wind shear, and convective asymmetries in tropical cyclones. J. Atmos. Sci. 60, 366-376.

Cuxart, J., Bougeault, P., Redelsperger, J.L., 2000. A turbulence scheme allowing for mesoscale and large-eddy simulations. Quart. J. Roy. Meteor. Soc. 126, 1-30.

DeMaria, M., DeMaria, R.T., Knaff, J.A., Molenar, D., 2012. Tropical cyclone lightning and rapid intensity change. Mon. Weather Rev. 140, 1828-1842. http://dx.doi.org/10. 1175/MWR-D-11-00236.1.

Fierro, A.O., Reisner, J.M., 2011. High-resolution simulation of the electrification and lightning of hurricane Rita during the period of rapid intensification. J. Atmos. Sci. 68, 477-494.

Fierro, A.O., Gilmore, M.S., Mansell, E.R., Wicker, L.J., Straka, J.M., 2006. Electrification and lightning in an idealized boundary-crossing supercell simulation of 2 June 1995. Mon. Weather Rev. 134, 3149-3172.

Fierro, A.O., Leslie, L., Mansell, E., Straka, J., MacGorman, D., Ziegler, C., 2007. A highresolution simulation of microphysics and electrification in an idealized hurricanelike vortex. Meteorol. Atmos. Phys. 98, 13-33.

Fierro, A.O., Shao, X.M., Hamlin, T., Reisner, J.M., Harlin, J., 2011. Evolution of eyewall convective events as indicated by intracloud and cloud-to-ground lightning activity during the rapid intensification of hurricanes Rita and Katrina. Mon. Weather Rev. 139, 1492-1504

Fierro, A.O., Mansell, E.R., Ziegler, C.L., MacGorman, D.R., 2015. Explicitly simulated electrification and lightning within a tropical cyclone based on the environment of hurricane Isaac (2012). J. Atmos. Sci. 72, 4167-4193. http://dx.doi.org/10.1175/JASD-14-0374.1.

Fovell, R.G., Corborsiero, K.L., Kuo, H.C., 2009. Cloud microphysics impact on hurricane track as revealed in idealized experiments. J. Atmos. Sci. 66, 1764-1778. http://dx. doi.org/10.1175/2008JAS2874.1.

Franklin, C.N., Holland, G.J., May, P.T., 2005. Sensitivity of tropical cyclone rainbands to ice-phase microphysics. Mon. Weather Rev. 133, 2473-2493.

Gao, S., Ran, L., Li, X., 2006. Impacts of ice microphysics on rainfall and thermodynamic processes in the tropical deep convection regime: a 2D cloud-resolving modeling study. Mon. Weather Rev. 134, 3015-3024.
Gish, O.H., 1944. Evaluation and interpretation of the columnar resistance of the atmosphere. Terr. Magn. Atmos. Electr. 49, 159-168.

Gregory, D., Morcrette, J.J., Jakob, C., Beljaars, A.M., Stockdale, T., 2000. Revision of convection, radiation and cloud schemes in the ECMWF model. Quart. J. Roy. Meteor. Soc. 126, 1685-1710.

Hallett, J., Mossop, S.C., 1974. Production of secondary ice particles during the riming process. Nature 249, 26-86.

Helsdon, J.H., Wojcik, W.A., Farley, R.D., 2001. An examination of thunderstorm charging mechanism using a two-dimensional storm electrification model. J. Geophys. Res. $106,1165-1192$.

Holland, G.J., 1980. An analytical model of wind and pressure profile in hurricanes. Mon. Weather Rev. 108, 1212-1218.

Jayaratne, R., Saunders, C.P.R., Halland, J., 1983. Laboratory studies of the charging of soft hail during ice crystal interactions. Quart. J. Roy. Meteor. Soc. 103, 609-630.

Jiang, H., Ramirez, E.M., Cecil, D.J., 2013. Convective and rainfall properties of tropical cyclone inner core and rainbands from 11 years of TRMM data. Mon. Weather Rev. 141, 431-450.

Khain, A., Cohen, N., Lynn, B., Pokrovsky, A., 2008. Possible aerosol effects on lightning activity and structure of hurricanes. J. Atmos. Sci. 65, 3652-3677.

Kuhlman, K.M., Ziegler, C.L., Mansell, E.R., MacGorman, D.R., Straka, J.M., 2006. Numerically simulated electrification and lightning of the 29 June 2000 STEPS supercell storm. Mon. Weather Rev. 134 (10), 2734-2757.

Li, X., Pu, Z., 2008. Sensitivity of numerical simulation of early rapid intensification of hurricane Emily (2005) to cloud microphysical and planetary boundary layer parameterizations. Mon. Weather Rev. 136, 4819-4838. http://dx.doi.org/10.1175/ 2008MWR2366.1.

Li, J., Wang, G., Lin, W., He, Q., Feng, Y., Mao, J., 2013a. Cloud-scale simulation study of Typhoon Hagupit (2008) Part I: Microphysical processes of the inner core and three-dimensional structure of the latent heat budget. Atmos. Res. 120-121, 170-180. http://dx.doi.org/10.1026/j.atmosres.2012.08.015.

Li, J., Wang, G., Lin, W., He, Q., Feng, Y., Mao, J., 2013b. Cloud-scale simulation study of Typhoon Hagupit (2008) Part II: Impact of cloud microphysical latent heat processes on typhoon intensity. Atmos. Res. 120-121, 202-215. http://dx.doi.org/10.1026/j. atmosres.2012.08.018.

Lin, Y.L., Farley, R.D., Orville, H.D., 1983. Bulk parameterization of the snow field in a cloud model. J. Clim. Appl. Meteorol. 22, 1065-1092.

Locatelli, J.D., Hobbs, P.V., 1974. Fall speeds and masses of solid precipitation particles. J. Geophys. Res. 79, 2185-2197.

Lord, S.J., Willoughby, H.E., Pietrowicz, J.M., 1984. Role of a parameterized ice-phase microphysics in an axisymmetric nonhydrostatic tropical cyclone model. J. Atmos. Sci. 41, 2836-2848.

Lyons, W.A., Nelson, T.E., Williams, E.R., Cramer, J.A., Turner, T.R., 1998. Enhanced positive cloud-to-ground lightning in thunderstorms ingesting smoke from fires. Science 282, 77-80.

Mansell, E.R., Ziegler, C.L., 2013. Aerosol effects on simulated storm electrification and precipitation in a two-moment bulk microphysics model. J. Atmos. Sci. 70, 2032-2050. http://dx.doi.org/10.1175/JAS-D-12-0264.1.

Mansell, E.R., MacGorman, D., Ziegler, C.L., Straka, J.M., 2002. Simulated three-dimensional branched lightning in a numerical thunderstorm model. J. Geophys. Res. 107 http://dx.doi.org/10.1029/2000JD000244.

Mansell, E.R., MacGorman, D.R., Ziegler, C.L., Straka, J.M., 2005. Charge structure and lightning sensitivity in a simulated multicell thunderstorm. J. Geophys. Res. 110. http://dx. doi.org/10.1029/2004JD005287.

Marshall, T.C., MacCarthy, M.P., Rust, W.D., 1995. Electric field magnitudes and lightning initiation in thunderstorms. J. Geophys. Res. 100, 7097-7103.

McBride, J.L., Zehr, R., 1981. Observational analysis of tropical cyclone formation. Part II: Comparison of non-developing versus developing systems. J. Atmos. Sci. 38 1132-1151.

McFarquhar, G.M., Zhang, H., Heymsfield, G., Hood, R., Dudhia, J., Halverson, J.B., Marks Jr., F., 2006. Factors affecting the evolution of Hurricane Erin (2001) and the distributions of hydrometeors: role of microphysical processes. J. Atmos. Sci. 63, 127-150.

Mlawer, E.J., Taubman, S.J., Brown, P.D., Iacono, M.J., Clough, S.A., 1997. Radiative transfer for inhomogeneous atmospheres: RRTM, a validated correlated-k model for the longwave. J. Geophys. Res. 102D, 16663-16682.

Nuissier, O., Rogers, R.F., Roux, F., 2005. A numerical simulation of Hurricane Bret on 22-23 August 1999 initialized with airborne Doppler radar and dropsonde data. Quart. J. Roy. Meteor. Soc. 131, 155-194.

Pinty, J.P., Jabouille, P., 1998. A mixed-phase cloud parameterization for use in mesoscale non hydrostatic model: simulations of a squall line and of orographic precipitations. Notepaper Presented at Conference of Cloud Physics, Everett, WA, USA.

Pinty, J.P., Barthe, C., Defer, E., Richard, E., Chong, M., 2013. Explicit simulations of electrified clouds: from idealized to real case studies. Atmos. Res. 123, 82-92. http://dx.doi. org/10.1016/j.atmosres.2012.04.008.

Price, C., Asfur, M., Yair, Y., 2009. Maximum hurricane intensity preceded by increase in lightning frequency. Nat. Geosci. 2, 329-332.

Proestakis, E., Kazadzis, S., Lagouvardos, K., Kotroni, V., Kazantzidis, A., 2016. Lightning activity and aerosols in the mediterranean region. Atmos. Res. 170, 66-75. http:// dx.doi.org/10.1016/j.atmosres.2015.11.010.

Reinhart, B., Fuelberg, H., Blakeslee, R., Mach, D., Heymsfield, A. Bansemer, A. Durden, S.L. Tanelli, S., Heymsfield, G., Lambrigsten, B., 2014. Understanding the relationships between lightning, cloud microphysics, and airborne radar-derived storm structure during Hurricane Karl (2010). Mon. Weather Rev. 142, 590-605.

Reisner, J.M., Jeffery, C.A., 2009. A smooth cloud model. Mon. Weather Rev. 137 1825-1843.

Rosenfeld, D., Woodley, W.L., Khain, A., Cotton, W.R., Carrió, G., Ginis, I., Golden, J.H., 2012 Aerosol effects on microstructure and intensity of tropical cyclones. Bull. Am. Meteorol. Soc. 93, 987-1001. http://dx.doi.org/10.1175/BAMS-D-11-00147.1. 
Saunders, C.P.R., Peck, S.L., 1998. Laboratory studies of the influence of the rime accretion rate on charge transfer during crystal/graupel collisions. J. Geophys. Res. 103, 13949-13956.

Saunders, C.P.R., Keith, W.D., Mitzeva, R.P., 1991. The effect of liquid water on thunderstorm charging. J. Geophys. Res. 96, 11007-11017.

Squires, K., Businger, S., 2008. The morphology of eyewall lightning outbreak in two category 5 hurricanes. Mon. Weather Rev. 136, 1706-1726.

Stern, D.P., Brisbois, J.R., Nolan, D.S., 2014. An expanded dataset of hurricane eyewall sizes and slopes. J. Atmos. Sci. 71, 2747-2762. http://dx.doi.org/10.1175/JAS-D-13-0302.1.

Stolz, D.C., Rutledge, S.A., Pierce, J.R., 2015. Simultaneous influences of thermodynamics and aerosols on deep convection and lightning in the tropics. J. Geophys. Res. Atmos. 120, 6207-6231. http://dx.doi.org/10.1002/2014JD023033.

Straka, J.M., Mansell, E.R., 2005. A bulk microphysics parameterization with multiple ice precipitation categories. J. Appl. Meteorol. 44, 445-466.

Takahashi, T., 1978. Riming electrification as a charge generation mechanism in thunderstorms. J. Atmos. Sci. 35, 1536-1548.

Tan, Y.B., Shi, Z., Chen, Z., Peng, L., Yang, Y., Guo, X., Chen, H., 2015. A numerical study of aerosol effects on electrification of thunderstorms. J. Atmos. Sol. Terr. Phys. http://dx. doi.org/10.1016/j.jastp.2015.11.006

Tan, Y.B., Peng, L., Shi, Z., Chen, H.R., 2016. Lightning flash density in relation to aeroso over Nanjing (China). Atmos. Res. 174-175, 1-8. http://dx.doi.org/10.1016/j. atmosres.2016.01.009.

Tsenova, B., Barthe, C., Mitzeva, R., Pinty, J.P., 2013. Impact of parameterization of ice particle charging based on rime accretion rate and effective water content on simulated with Méso-NH thunderstorm charge distributions. Atmos. Res. 128, 85-97.

Vié, B., Pinty, J.P., Berthet, S., Leriche, M., 2016. LIMA (v1.0): a quasi two-moment microphysical scheme driven by a multimodal population of cloud condensation and ice freezing nuclei. Geosci. Model Dev. 9, 567-586. http://dx.doi.org/10.5194/gmd-9567-2016 (http://www.geosci-model-dev.net/9/567/2016/)

Wang, Y., Wan, Q., Meng, W., Liao, F., Tan, H., Zhang, R., 2011. Long-term impacts of aerosols on precipitation and lightning over the pearl river delta megacity area in
China. Atmos. Chem. Phys. 11, 12421-12436. http://dx.doi.org/10.5194/acp-1112421-2011 (http://www.atmos-chem-phys.net/11/12421/2011/).

Whittaker, I.C., Douma, E., Rodger, C.J., Marshall, T.J.C.H., 2015. A quantitative examination of lightning as a predictor of peak winds in tropical cyclones. J. Geophys. Res. Atmos. 120, 3789-3801. http://dx.doi.org/10.1002/2014JD022868.

Williams, E.R., 1989. The tripole structure of thunderstorms. J. Geophys. Res. 94, 13151-13167. http://dx.doi.org/10.1029/JD094iD11p13151.

Willoughby, H.E., Jin, H.L., Lord, S.J., Piotrowicz, J.M., 1984. Hurricane structure and evolution as simulated by an axisymmetric, nonhydrostatic numerical model. J. Atmos. Sci. $41,1169-1186$.

Wu, C.C., Cheng, H.J., Wang, Y., Chou, K.H., 2009. A numerical investigation of the eyewall evolution in a landfalling typhoon. Mon. Weather Rev. 137, 21-40.

Yuan, T., Remer, L.A., Pickering, K.E., Yu, H., 2011. Observational evidence of aerosol enhancement of lightning activity and convective invigoration. Geophys. Res. Lett. 38. http://dx.doi.org/10.1029/2010GL046052 (n/a-n/a).

Yuter, S.E., Houze Jr., R.A., 1995. Three-dimensional kinematic and microphysical evolution of Florida cumulonimbus. Part II: Frequency distributions of vertical velocity, reflectivity and differential reflectivity. Mon. Weather Rev. 123, 1941-1963.

Zhang, W., Zhang, Y., Zheng, D., Zhou, X., 2012. Lightning distribution and eyewall outbreaks in tropical cyclones during landfall. Mon. Weather Rev. 140, 3573-3586.

Zhang, W., Zhang, Y., Zheng, D., Wang, F., Xu, L., 2015. Relationship between lightning activity and tropical cyclone intensity over the Northwest Pacific. J. Geophys. Res. Atmos. 120, 4072-4089. http://dx.doi.org/10.1002/2014JD022334.

Zhu, T., Zhang, D.L., 2006. Numerical simulation of Hurricane Bonnie (1998): sensitivity to varying cloud microphysical processes. J. Atmos. Sci. 63, 109-126.

Ziegler, C.L., MacGorman, D.R., Dye, J.E., Ray, P.S., 1991. A model evaluation of noninductive graupel-ice charging in the early electrification of a mountain thunderstorm. J. Geophys. Res. 96, 12,833-12,855.

Zipser, E.J., Lutz, K.R., 1994. The vertical profile of radar reflectivity of convective cells: a strong indicator of storm intensity and lightning probability? Mon. Weather Rev. 122, 1751-1759. 